\title{
Immature stages and biology of the enigmatic oxyporine rove beetles, with new data on Oxyporus larvae from the Russian Far East (Coleoptera: Staphylinidae)
}

\author{
Alexandra TOKAREVA ${ }^{1, *)}$, Alexey SOLODOVNIKOV²) \& Fedor KONSTANTINOV ${ }^{1,3)}$ \\ ${ }^{1)}$ Department of Entomology, Faculty of Biology, St. Petersburg State University, Universitetskaya nab. 7/9, St. Petersburg 199034, Russia \\ 2) Natural History Museum of Denmark, Zoological Museum, Universitetsparken 15, Copenhagen 2100, Denmark \\ 3) Zoological Institute, Russian Academy of Sciences, Universitetskaya nab. 1, St. Petersburg 199034, Russia \\ *) corresponding author: e-mail: alexan4tok@gmail.com.
}

Accepted:

$21^{\text {st }}$ March 2020

Published online: $31^{\text {st }}$ March 2020

\begin{abstract}
Oxyporinae are a visually attractive and highly specialized mycophagous subfamily of rove beetles (Staphylinidae) with enigmatic origins and a largely unknown evolutionary history. Our knowledge of their immature stages and biology, valuable for solving questions about their phylogeny, is still very fragmentary. Here, we describe for the first time the larval morphology of Oxyporus (s. str.) procerus Kraatz, 1879 and O. (Pseudoxyporus) melanocephalus Kirschenblatt, 1938, both from the Russian Far East. We redescribe the larval morphology of the widespread $O$. (s. str.) maxillosus Fabricius, 1775 based on material, also from the Russian Far East. All larvae are identified based on the combined evidence from rearing and coxl barcoding. For $O$. maxillosus, $O$. procerus and $O$. (P.) melanocephalus we provide some new field and laboratory-based data on feeding, mating, oviposition, female brood care, duration of larval development, and behavior. We applied the Atheta-based system of Ashe \& Watrous (1984) to describe and compare the chaetotaxy of these Oxyporus larvae. We extract the most essential comparable data for all species of Oxyporus with known larvae from poorly compatible published larval descriptions with dubious homology assessments for their chaetotaxy. In addition, data on fungal hosts and beetle biology is summarized for the genus and provided for each species. New morphological traits are revealed for the Oxyporus larvae. Significant differences in larval morphology, reproduction behavior and cox 1 barcoding region between the subgenera Oxyporus s. str. and Pseudoxyporus Nakane \& Sawada, 1956 correspond to the morphological distance between their adults and suggest that they may be potentially elevated to genus rank.
\end{abstract}

Key words. Coleoptera, Staphylinidae, Oxyporinae, immature stages, larval morphology, chaetotaxy, brood care, fungivory, mycophagy, Russian Far East, Palaearctic Region

Zoobank: http://zoobank.org/urn:lsid:zoobank.org:pub:BE18A83D-CDFC-4B02-82E8-A50E66E32C27

(C) 2020 The Authors. This work is licensed under the Creative Commons Attribution-NonCommercial-NoDerivs 3.0 Licence.

\section{Introduction}

Rove beetles (Staphylinidae) are an exceptionally species-rich and ecologically diverse lineage of Coleoptera. The majority of species in this family are predators, closely followed by fungivores and saprophages (THAYER 2016). Among the fungivores, Oxyporinae are especially noteworthy. It is a relatively small subfamily with more than one hundred described species in a single recent genus Oxyporus Fabricius, 1775 which is confined to Eurasia and North and South America (Herman 2001, CampBell 1969). Species in this genus are closely associated with fungi because their adults and larvae live inside fleshy fruit bodies of fungi and feed on them (SCHEERPELTZ \& HÖFLER 1948; Tichomirova 1973; McCabe \& Teale 1981; NewTON 1984; Leschen \& Allen 1988; Hanley \& Goodrich 1994, 1995; Hanley \& Setsuda 1999; Hwang et al. 2002). Species of Oxyporus are highly adapted to such a mode of life. Adults have specially modified mandibles to chew 
Table 1. Summary of published and new data on Oxyporus immature stages. Abbreviations: E - eggs, L3 - third instar larvae, P - pupae

\begin{tabular}{|c|c|c|}
\hline Species & Published or new data & Reference \\
\hline \multicolumn{3}{|l|}{ Subgenus Oxyporus s.str. } \\
\hline \multirow{2}{*}{$\begin{array}{l}\text { Oxyporus (Oxyporus) femoralis } \\
\text { Gravenhorst, } 1802\end{array}$} & Morphology: E, L3 (without chaetotaxy), P & LESCHEN \& AlLEN (1988) \\
\hline & Biology: duration of life stages, feeding, host fungi (larvae and adults) & \\
\hline \multirow{2}{*}{$\begin{array}{l}\text { Oxyporus (Oxyporus) germanus Sharp, } \\
1889\end{array}$} & Morphology: E, L3 (incl. chaetotaxy), P & HWANG \& AHN (2002) \\
\hline & Biology: duration of life stages, host fungi, feeding & \\
\hline \multirow{3}{*}{$\begin{array}{l}\text { Oxyporus (Oxyporus) japonicus Sharp, } \\
1889\end{array}$} & Morphology: E, L3 (incl. chaetotaxy), P & HANLEY \& SETSUDA \\
\hline & Biology: duration of life stages, host fungi, feeding & $(1999)$ \\
\hline & Biology: brood care & SETSUDA (1994) \\
\hline \multirow{2}{*}{$\begin{array}{l}\text { Oxyporus (Oxyporus) major Gravenhorst, } \\
1806\end{array}$} & Morphology: E, L3 (incl. chaetotaxy) & HANLEY \& GOODRICH \\
\hline & Biology: duration of life stages, host fungi, feeding & $(1995)$ \\
\hline \multirow{5}{*}{$\begin{array}{l}\text { Oxyporus (Oxyporus) maxillosus } \\
\text { Fabricius, } 1793\end{array}$} & Morphology: L3 (without chaeotaxy) & PAULian (1941) \\
\hline & Biology: notes on feeding, mating & SCHIøDTE (1864) \\
\hline & Biology: duration of life stages & $\begin{array}{l}\text { SCHEERPELTZ \& HÖFLER } \\
(1948)\end{array}$ \\
\hline & Morphology: E, L3 (incl. chaetotaxy) & this paper \\
\hline & $\begin{array}{l}\text { Biology: duration of life stages, feeding, mating, brood care, host fungi } \\
\text { (larvae and adults) }\end{array}$ & \\
\hline \multirow{2}{*}{$\begin{array}{l}\text { Oxyporus (Oxyporus) procerus Kraatz, } \\
1879\end{array}$} & Morphology: E, L3 (incl. chaetotaxy) & this paper \\
\hline & Biology: feeding, host fungi (larvae and adults) & \\
\hline \multirow{2}{*}{$\begin{array}{l}\text { Oxyporus (Oxyporus) rufus Linnaeus, } \\
1758\end{array}$} & Morphology (first for the genus): L3 (general view) & HEEGER (1853) \\
\hline & Biology: mycophagy (first report), feeding (larva), mating & \\
\hline \multirow[t]{2}{*}{ Oxyporus (Oxyporus) stygicus Say, 1834} & Morphology: E, L3 (incl. chaetotaxy), P & HANLEY \& GOODRICH \\
\hline & Biology: host fungi & (1994). \\
\hline \multirow{4}{*}{$\begin{array}{l}\text { Oxyporus (Oxyporus) vittatus } \\
\text { Gravenhorst, } 1802\end{array}$} & Morphology (O. vittatus): E, L3 (without chaetotaxy), $\mathrm{P}$ & LESCHEN \& ALLEN (1988) \\
\hline & Biology: duration of life stages, feeding, host fungi (larvae and adults) & \\
\hline & Morphology: L3 (notes) & HANLEY \& GOODRICH \\
\hline & Biology: host fungi & (1994). \\
\hline \multicolumn{3}{|l|}{ Subgenus Pseudoxyporus } \\
\hline \multirow{3}{*}{$\begin{array}{l}\text { Oxyporus (Pseudoxyporus) lateralis } \\
\text { Gravenhorst, } 1802\end{array}$} & Morphology: L3 (brief notes) & PaUlian (1941) \\
\hline & Biology: host fungi (larvae) & \\
\hline & Morphology: L3 redescription (without chaetotaxy) & McCaBe \& Teale (1981) \\
\hline \multirow{2}{*}{$\begin{array}{l}\text { Oxyporus (Pseudoxyporus) } \\
\text { melanocephalus Kirschenblatt, } 1938\end{array}$} & Morphology: E, L3 (incl. chaetotaxy) & this paper \\
\hline & $\begin{array}{l}\text { Biology: duration of life stages (from E to prepupa), feeding, mating, brood } \\
\text { care, host fungi (larvae and adults) }\end{array}$ & \\
\hline \multirow{4}{*}{$\begin{array}{l}\text { Oxyporus (Pseudoxyporus) occipitalis } \\
\text { Fauvel, } 1864\end{array}$} & Morphology: L3 (brief notes) & Paulian (1941) \\
\hline & Morphology: E, L3 (without chaetotaxy), P & LESCHEN \& AlLEN (1988) \\
\hline & Biology: duration of life stages, feeding, host fungi (larvae and adults) & \\
\hline & Biology: life history, host fungi & $\begin{array}{l}\text { HANLEY \& GOODRICH } \\
\text { (1993). }\end{array}$ \\
\hline
\end{tabular}

through the fungal tissue and a notably short duration of metamorphosis fitting with the short-living fungal fruit body (Leschen \& Allen 1988; Hanley \& Goodrich 1993, 1994, 1995a,b). Morphologically, adult oxyporines are very peculiar and cannot be confused with any other rove beetles (Figs 1-3). It is not surprising that hitherto suggested hypotheses about their sister-group relationships within the family Staphylinidae are highly controversial. Historically they ranged from Oxyporus being member of Oxytelinae (i.e. LeConte 1861, FAuvel 1872, LeConte \& HoRn 1883) or a group placed close to some current Quediini-like tribes of Staphylininae (ERICHSON 1839). Modern authors place Oxyporinae as a sister taxon to the Stenine group of subfamilies (HANSEN 1997, HunT et al. 2007), a sister subfamily to Megalopsidiinae (GreBEnNIKov 2009) or to Leptotyphlinae (McKenNA et al. 2015). The internal phylogeny and the global diversity of Oxyporus has never been assessed. NAKANE \& SAWADA (1956), in the revision of Japanese species, divided the genus Oxyporus in two genera, Oxyporus s. str. and Pseudoxyporus Nakane \&
Sawada, 1956. However, CAmpBell (1969) in his revision of the new world Oxyporinae downgraded them to subgenera of Oxyporus s. 1.

Recently discovered well preserved rock fossils (YuE et al. 2011, CAI \& HuANg 2014) and Burmese amber inclusions (CAI et al. 2016) of Oxyporinae from the Early and Middle Cretaceous respectively, indicate that the group was already abundant back then. YUE et al. (2011) assigned their partially preserved species to the extant genus Oxyporus, while CAI \& HuANG (2014) described the extinct genera Cretoxyporus Cai \& Huang, 2014 and Protoxyporus Cai \& Huang, 2014. CAI et al. (2016), based on the fossil evidence, claimed an ancient association of Oxyporinae with agaricoid fungi. It seems that the puzzle of the evolutionary origin and diversification of Oxyporinae can be solved only by pulling together the evidence from extant and extinct species, morphology of adults and larvae, genomics and natural history. Detailed knowledge of the immature stages and biology of Oxyporinae is also important for understanding their tight coevolution with the fungi. 

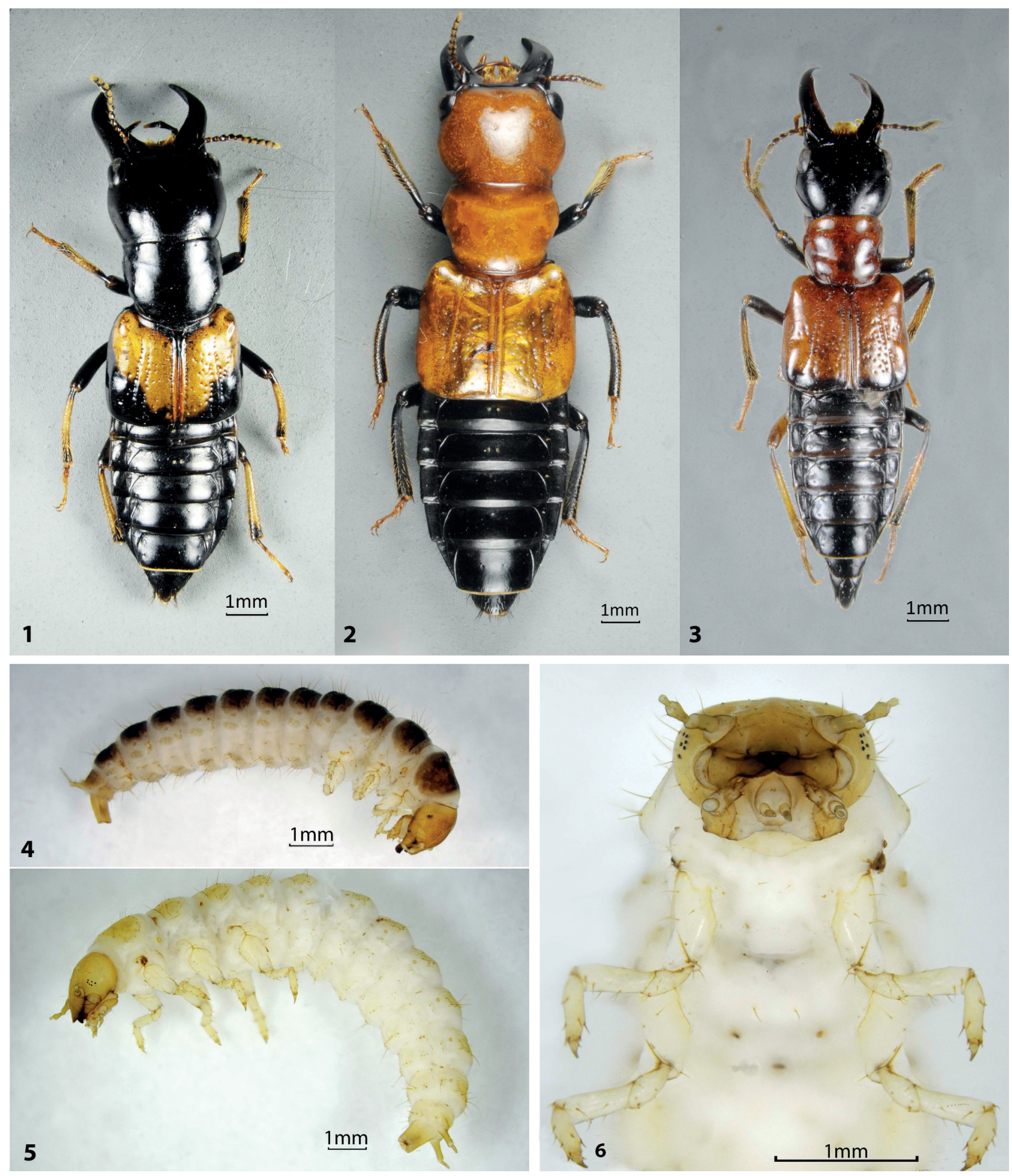

Figs 1-6. Third instar larvae and adults of Oxyporus spp. general view. 1 - imago of $O$. maxillosus Fabricius, 1775, dorsal view; 2 -imago of $O$. procerus Kraatz, 1879, dorsal view; 3 - imago of $O$. (P.) melanocephalus Kirschenblatt, 1938, dorsal view; 4 - larva of $O$. maxillosus, lateral view; 5 - larva of $O$. (P.) melanocephalus, lateral view; 6 - larva of $O$. (P.) melanocephalus, head and thorax in ventral view.

Until the present study, data on morphology and biology of the immature stages were available only for 10 species of Oxyporus (Table 1), which is clearly insufficient in relation to the actual species diversity of this genus. Among them, the chaetotaxy, a character set crucial for the diagnostic and phylogenetic use of immature insects (VAN EMDEN 1957; MaKarov 2002, 2008; Solodovnikov 2007; Meier \& Lim 2009) was studied for four species only. Various details of feeding, reproduction and other elements of biology remain unknown for the majority of Oxyporinae species. In order to fill some of the mentioned knowledge gaps, the senior author (AT) spent one field season in the Russian Far East collecting adult and larval Oxyporus, rearing them in the laboratory and making biological observations. The reason to choose this area of the Palaearctic Region was its relatively rich fauna of Oxyporus and its accessibility. 
This paper provides detailed descriptions of the previously unknown larval morphology of $O$. (P.) melanocephalus Kirschenblatt, 1938 and $O$. (s. str.) procerus Kraatz, 1879, as well as a redescription of the third instar larva morphology of $O$. (s. str.) maxillosus Fabricius, 1775. Data permitting, it describes the feeding and mating biology of these species and incorporates all new observations into the entire pool of data about Oxyporus. This latter aspect became the most difficult part of this paper because of the highly fragmented, often incompatible nature of the previous publications on the subject. By providing a summary of what we reliably know about immature stages and biology of this genus, we lay a foundation for broader comparisons and define next steps for integration of these data in the study of Oxyporus phylogeny and systematics.

\section{Material and methods}

Rearing. Adults, eggs and larvae of all studied species were collected from the $25^{\text {th }}$ of August to the $23^{\text {rd }}$ of September, 2018 in the Arboretum and the Gornotaezhnaya Station surroundings, Far Eastern Branch of the Russian Academy of Sciences, Primorsky Region, Russia $\left[43.6945^{\circ} \mathrm{N}, 132.1520^{\circ} \mathrm{E}\right]$ (Figs 63, 64). Collecting was made during regular daily excursions when all spotted fungal fruit bodies were inspected for the presence of Oxyporus. All observed Oxyporus larvae or adults with their eggs layings were transferred to the station in individual bags with the respective fungus and placed into separate rearing boxes and kept at room temperature $\left(22-25^{\circ} \mathrm{C}\right)$. In total, we reared three species: $O$. maxillosus, $O$. procerus (all Oxyporus s. str.), and O. (Pseudoxyporus) melanocephalus. Unfortunately, larvae of two species haven't reached the adult stage. We reared $O$. maxillosus from eggs to imago, $O$. procerus from the second to the third instar, and $O$. $(P$.) melanocephalus from eggs to prepupae.

Each rearing box was made from two plastic containers $179 \times 132 \mathrm{~mm}, \mathrm{~h}=122 \mathrm{~mm}$, each, nested one in another (Fig. 65). Vertical sides were perforated in both containers, whereas the floor was perforated only in the inner container. The floor of the external container was covered with a paper wipe to accumulate moisture. Such double wall design of the rearing box allowed moderate evaporation to avoid excessive water condensation inside the container. The inner container was filled with a layer $(1.0-1.5 \mathrm{~cm})$ of almost dry sand and soil with leaf or coniferous litter layer (7-10 $\mathrm{cm}$ ) on top. Soil and leaf litter were dried at $60^{\circ} \mathrm{C}$ to avoid extra moisture and suppress mould.

In the field, eggs, larvae of all instars and adults were collected from various species of big and fleshy agaricoid Basidiomycetes with round caps. Each fungal fruit body was checked whether it contained a single female and its egg cluster or first instar larvae. Adults were preserved in $96 \%$ ethanol and cross-labeled with the respective rearing boxes where the host fungus and eggs or larvae were placed. Specimens from fungi with more than one chamber or with more than one egg cluster were not used for rearing to avoid incorrect species associations (in such cases, all specimens were preserved in $96 \%$ ethanol). During rearing, the most degraded fungal pieces left by the larvae were replaced with new pieces of the same fungus species to prevent excessive moisture and mould development which is dangerous for the larvae. Fresh fungi were collected beforehand and stored in the fridge. When the fungus is almost entirely consumed by larvae, the third instar larvae dig in the sand layer to pupate. At this stage all the fungal remnants were removed from the container to ensure a suitable level of humidity for prepupae and pupae.

Specimens used in this study are deposited at the collection of the Natural History Museum of Denmark (NHMD, former ZMUC), Copenhagen, Denmark.

Identification of fungal hosts. All well preserved fungal host species collected by AT were identified by Lyudmila Kalinina (Komarov Botanical Institute of the Russian Academy of Sciences, Saint Petersburg). Taxonomy of all fungal host species follows MycoBank (Crous 2004).

DNA barcoding and adult-larva matching. To allow unambiguous identification of the larvae via DNA-barcoding, a few third instar larvae and adults of all collected species were preserved in 96\% ethyl alcohol. DNA-extraction and PCR were performed at the Chromas Core Facility center of the St. Petersburg State University. The following set of adult and larval specimens were used for the barcoding:

Oxyporus (s. str.) maxillosus: one adult female and one third instar larva; the female was collected in a fungal fruit body in the chamber with eggs from which the sequenced larva were reared.

Oxyporus (s. str.) procerus: one adult female and one third instar larva. Larvae were found in a fungus already abandoned by adults; they were assumed to belong to this species because of their noticeably bigger size $(O$. procerus is the only species with such large body size in the Russian Far East fauna).

Oxyporus (Pseudoxyporus) melanocephalus: one adult female and one third instar larva. The female was found laying eggs between fungal gills, larvae were reared from these eggs.

Thus, the GenBank accession numbers (Table 2) are given for two of barcoded specimens of each species (one for the larva and one for the associated adult). Total DNA was extracted from the most intact exemplars. Extraction was done from one or two legs per specimen using Qiagen DNeasy Blood \& Tissue Kit; after crushing the exoskeleton, the sample was incubated at $56^{\circ} \mathrm{C}$ in $\mathrm{AE}$ buffer with proteinase $\mathrm{K}$ for about $24 \mathrm{~h}$. PCRs of the coxl were performed using Evrogen kit for Master Mix: $0,1 \mu \mathrm{l}$ Taq polymerase in a $25 \mu \mathrm{l}$ reaction mixture containing $1 \mu \mathrm{l}$ of each primer, 2 $\mu \mathrm{l}$ dNTPs, $2.5 \mu \mathrm{l}$ of Taq Buffer and $2 \mu \mathrm{l}$ of genomic DNA template. The primer pair LCO1490 (5'-GGTCAACAAATCATAAAGATATTGG-3') and HCO2198 (5'-TAAACTTCAGGGTGACAAAAAATCA-3') was used to amplify a $658 \mathrm{bp}$ fragment of the coxl gene (FoLMER et al. 1994). The thermal cycling program consisted of 35 cycles of $94^{\circ} \mathrm{C}$ for $30 \mathrm{sec}, 42^{\circ} \mathrm{C}$ for $30 \mathrm{sec}$ and $72^{\circ} \mathrm{C}$ for $45 \mathrm{sec}$, followed by a final extension at $72^{\circ} \mathrm{C}$ for $10 \mathrm{~min}$. Paired forward and reverse reads were assembled and edited in 
Geneious (v. 9.1). Assembled sequences were checked via BLAST to verify the needed PCR target and were aligned with the respective coxl fragments of Oxyporus rufus and $O$. maxillosus from NCBI. The matrix of genetic distances was calculated using the Kimura 2-parameter model of base substitution with MEGA X (KumAR et al. 2018) to confirm the accuracy of identification (Table 2).

Microscopy and illustrations. For the light microscopy larvae were boiled in 10\% $\mathrm{KOH}$ solution for ca. 2-4 min, or treated in $\mathrm{KOH}$ at room temperature for 10 hours, then rinsed in distilled water, dissected and mounted to the slides in glycerin-jelly. Observations, measurements and drawings of the chaetotaxy patterns were made under a Nikon SMZ 1500 stereomicroscope equipped with a camera lucida. Partially focused images of each specimen were taken with a Nikon D700 camera mounted on a Nikon SMZ 1500 stereomicroscope and subsequently stacked using the Helicon Focus 5.3.14 software. For more detailed examination of selected structures, a Leica DM2500 microscope with a camera lucida was used. Scanning electron micrographs were taken with a Hitachi TM3000 SEM at the Centre for Microscopy and Microanalysis (CMM) of the St. Petersburg State University, Saint Petersburg. Specimens for the SEM were first cleaned by immersing them in $1: 1$ solution of $96 \%$ ethanol and pure ethyl acetate in individual tubes and processed in an ultrasonic bath for 15 minutes. If this procedure was not sufficient, larvae were cleaned with a common washing detergent in water and then returned to the $96 \%$ ethanol solution through the stepwise replacement of water by ethanol.

Chaetotaxy systems and our homologies. The chaetotaxy schemes provided here follow the AsHE \& WATRous (1984) system for Atheta coriaria Kraatz, 1856 with deviations suggested by GoOdRich \& Hanley $(1994,1995)$. We also provide several additions related to new chaetotaxy elements previously undescribed for Oxyporus larvae, e.g. campaniform sensilla, pore-like structures or microsetae of the pronotal membrane.

Pore-like structures of chaetotaxy. Tergal sclerites of all three species have additional structures which resemble campaniform sensilla when examined under light microscope. Their examination by SEM revealed that they differ from typical campaniform sensilla of beetles (as illustrated e.g. by FrANTSEVITCH et al. 2015: figs 2a-g) by the absence of apparent cuticular rim and perforations on the cap and by a very subtle impression of the cuticle (Figs 59-62). Since the secure identification of these structures needs histological research, we call them here 'pore-like structures' $(p l s)$. They seem to display some serial homology on the thoracic tergites.

Abbreviations. E-eggs; L2, L3 - second and third instar larvae, respectively; $\mathbf{R}$ - number of reared specimens.

Head. Cd - cardo; Dmt - dorsal labial microtrichia; Ed - epicranial dorsal setae; Ec - epicranial campaniform sensilla; El - epicranial lateral setae; Fd - frontal dorsal cranial setae; Fc - frontal campaniform sensilla; Fl - frontal lateral cranial setae; Hyp - hypopharynx; L lateral cranial setae; Ld - labral dorsal setae; Ll - labral lateral setae; Ma - mala; Mnt - mentum; Pa - palpifer; Pc - posterior cranial campaniform sensillum; Pmnt prementum; Pvc, Pv1, Pv2 - premental ventral sensilla; Sa - sensory appendage; Smnt - submentum; Stp - stipes; $\mathbf{T}$ - temporal cranial setae; $\mathbf{V}$ - ventral setae; $\mathbf{V c}$ - ventral campaniform sensilla; Vl - ventrolateral cranial setae; Ic1- Ic4 - campaniform sensilla on antennomere I; IIIams - apical microseta on antennomere III; IIIs - solenidium on antennomere III.

Thorax and abdomen. A1-A4 - anterior tergal setae; c. s. - campaniform sensilla; D1-D3 - discoidal thoracic tergal setae; $\mathbf{M}$ - dorsal body membrane setae; $\mathbf{L}$ - lateral tergal setae; $\mathbf{P}$ - posterior tergal setae; pls - pore-like structures; Pyg - pygopod; P1-P5 - posterior tergal setae; TgIX - IX tergum; Ur - urogomphi.

Legs. Ad - anterodorsal leg setae; Al - anterolateral leg setae; $\mathbf{A v}$ - anteroventral leg setae; $\mathbf{C x}$ - coxa; D - dorsal leg setae; Fm - femur; Pd - posterodorsal leg setae; PI - posterolateral leg setae; Pv - posteroventral leg setae; $\mathbf{T b}$ - tibia; $\mathbf{T r}$ - trochanter; $\mathbf{T s}$ - tarsungulus; $\mathbf{V t}$ - ventral leg setae.

\section{Results}

Coxl sequences confirmed the species identification of the larvae of all three species studied here: in all three species, the $\operatorname{cox} 1$ sequences of adults and larvae were identical $(d=0.00)$. In addition, the distance was very low $(\mathrm{d}=0.01)$ between our specimens of $O$. maxillosus and two specimens of the same species from Germany, NCBI (Table 2). The positive identification of the larvae allows us to use them for the morphological study below.

Table 2. Pairwise nucleotide distance matrix of the barcoding COI region for Oxyporus adults and larvae. Genetic distances in terms of the number of base substitutions per site between sequences.

\begin{tabular}{|c|c|c|c|c|c|c|c|c|c|c|c|c|}
\hline Species and stage & Specimen ID & Genbank number & & 1 & 2 & 3 & 4 & 5 & 6 & 7 & 8 & 9 \\
\hline O. (P.) melanocephalus imago & NHMD620699 & MN508938 & 1 & & & & & & & & & \\
\hline O. (P.) melanocephalus larva & NHMD620698 & MN508939 & 2 & 0.00 & & & & & & & & \\
\hline O. procerus larva & NHMD620700 & MN508940 & 3 & 0.17 & 0.17 & & & & & & & \\
\hline O. procerus imago & NHMD620701 & MN508941 & 4 & 0.18 & 0.18 & 0.00 & & & & & & \\
\hline O. maxillosus imago & NHMD620703 & MN508942 & 5 & 0.19 & 0.19 & 0.07 & 0.07 & & & & & \\
\hline O. maxillosus larva & NHMD620702 & MN508943 & 6 & 0.19 & 0.19 & 0.07 & 0.07 & 0.00 & & & & \\
\hline O. maxillosus imago (NCBI) & ZFMK-TIS-5813 & KU918803.1 & 7 & 0.18 & 0.18 & 0.07 & 0.07 & 0.00 & 0.00 & & & \\
\hline O. maxillosus imago (NCBI) & ZFMK-TIS-2515804 & KU915151.1 & 8 & 0.18 & 0.18 & 0.07 & 0.07 & 0.00 & 0.00 & 0.00 & & \\
\hline O. rufus imago (NCBI) & ZMUO006011 & KJ965221.1 & 9 & 0.16 & 0.16 & 0.12 & 0.12 & 0.11 & 0.11 & 0.11 & 0.11 & \\
\hline O. rufus imago (NCBI) & ZFMK-TIS-8230 & KU915441.1 & 10 & 0.16 & 0.16 & 0.12 & 0.12 & 0.11 & 0.11 & 0.11 & 0.11 & 0.01 \\
\hline
\end{tabular}


We also critically revised previously published data and provide short diagnoses of their third instars. Chaetotaxy of the larvae is summarized in Table 3.

\section{Larval morphology}

\section{Genus Oxyporus Fabricius, 1775}

Description of third instar larva. Body white, with thoracic and abdominal terga yellow, grey, brown or without pigmentation, rather large ( 6.0 to $20.9 \mathrm{~mm}$ ), elongate, slightly dorso-ventrally curved, parallel-sided.

Head. Yellow to brown or without pigmentation, prognathous, oval. Ecdysial lines distinct, Y-shaped, with lateral arms complete, running to bases of antennae. Epicranium with a pair of six stemmata in two vertical rows of unequal length (Figs 5,6). Setation composed of simple setae, microsetae less than $1 / 4$ length of average seta, and campaniform sensilla. Setae arranged in frontal dorsal and frontal lateral rows $(F d, F l)$, epicranial dorsal and epicranial lateral rows $(E d, E l)$, temporal rows $(T)$, and lateral rows $(L)$. Campaniform sensilla (c. s.) arranged in stable pattern, corresponding with setal rows. Antennae short, three-segmented: antennomere I elongate, narrowed towards middle, asetose, with four campaniform sensilla; antennomere II trisetose, with one campaniform sensillum, tubercle-like sensory appendage with distinct basal collar (SA1), and narrow simple conical sensory appendage ( $S A 2)$ (Fig. 41); antennomere III small, with three apical setae and superior group of small sensilla consisting of one thickened membranous solenidium (IIIs3), two narrow spiny solenidia (IIs 1, IIs 2), and one microseta (IIIams), as in O. procerus (Fig. 41). Nasale serrate; dorsal nasal setae include labral lateral and labral lateral setae $(L d, L l)$ (Figs 45, 46). Epipharynx with multiple microtrichia and median furrow. Mandibles broad basally, flattened laterally, apically bicupsidate, with serrate lobes, prostheca absent. Maxillae with small triangular precardial sclerite; cardo triangular, with one seta; stipes short, with three setae and one campaniform sensillum; mala trilobed, with two non-articulated usually short wide spines on inner and middle lobes, and one non-articulated spine, two articulated setae and two campaniform sensilla on outer lobe. Maxillary palpi three-segmented; palpifer divided into two membranous parts with one seta on proximal part and seta and campaniform sensillum on distal part; palpomere I asetose with one campaniform sensillum; palpomere II with two setae and two or one campaniform sensillum; palpomere III asetose with campaniform sensillum. Labium fused to hypopharynx, forming membranous flexible socket, with two setae on submentum, two setae and two microsetae on mentum, and group of usually two setae and campaniform sensilla $(P v 1, P v 2, P c)$ on prementum at base of each labial palpus; labial apex with two setae and half-ring of tiny microtrichia ventrally on hypopharyngeal part; labial palpus two-segmented, asetose.

Thorax. Tergites transverse, moderately sclerotized. Pronotum broadly oval, with narrow membranous area along midline; setation with anterior $(A)$, discal $(D)$, lateral $(L)$, and posterior $(P)$ rows of setae in each half.
Membrane anterior to pronotum in some species with four microsetae M1-M4 or some of them. Mesonotum transverse, with anterior, lateral and posterior rows of setae. Membrane anterior to mesonotum usually with four microsetae M1-M4. Metanotum transverse, with anterior, lateral and posterior rows of setae. Membrane anterior to metanotum with four or less microsetae M1-M4.

Legs. All legs with uniform setation. Coxa, trochanter, femur, tibia, and tarsungulus with 18, eight, eight, nine and two setae, respectively.

Abdomen. Tergites transverse. Membrane anterior to abdominal tergum I with two or three microsetae. Tergite IX with one or two pairs of microsetae anteriorly and up to four pairs of average length setae posteriorly. Urogomphus two-segmented; segment I with four to six setae on apical part; segment II narrower, with one short ventral seta and two longer apical setae. Pygopod or abdominal segment X slightly tapered from base to apex, setation of 16-24 setae, usually asymmetrically arranged.

\section{Subgenus Oxyporus s. str.}

\section{Oxyporus (Oxyporus) maxillosus Fabricius, 1793 (Figs 1, 4, 7-27)}

Material examined. 28 third instar larvae (NHMD): RUSSIA: PRIMORSKY TERRITORY: Arboretum of the Gornotaezhnaya Station FEB RAS, $43.6945498^{\circ} \mathrm{N}, 132.1520375^{\circ} \mathrm{E}, 11 . i x .2018$, from Armillaria sp., A. Tokareva leg. Two adults and 26 larvae were reared by A. Tokareva (rearing R28) from eggs collected in the fungus.

DNA bardcoding. 1 third instar larva (NHMD620702: GenBank Accession No.: MN508943) and one associated adult (NHMD620703: GenBank Accession No: MN508942).

Diagnosis. Larva of $O$. maxillosus differs from all other described Oxyporus larvae by the following set of chaetotaxy characters: five posterior $(P)$ setae on each side of thoracic tergite I and six lateral $(L)$ setae on each side of thoracic tergite II. Oxyporus maxillosus larva further differs from $O$. procerus by having three membrane setae on each side before thoracic tergite I (M2-M4); four anterior setae $(A 1-A 4)$ and five posterior setae $(P 1-P 5)$ on each side of thoracic tergite I, six lateral setae $(L 1-L O)$ on each side of thoracic tergite II. From O. melanocephalus it differs by the following characters: two transversal setae on each side of the head capsule (T1-T2); three membrane setae on each side before thoracic tergite I (M1-M3); four anterior $(A 1-A 4)$, three discoidal (D1$D 3)$, six lateral (L1-L6), and five posterior setae (P1-P5) on each side of thoracic tergite I; six anterior $(A 1-A 6)$, six lateral $(L 1-L 6)$, and six posterior setae $(P 1-P 6)$ on each side of thoracic tergite II; six anterior $(A 1-A 6)$, six lateral $(L 1-L 6)$, and six posterior setae $(P 1-P 6)$ on each side of thoracic tergite III; three anterior $(A 1-A 3)$, four lateral $(L 1-L 4)$, and five posterior setae $(P 1-P 5)$ on each side of abdominal tergite (Table 3 ).

Redescription. Eggs ( $\mathrm{n}=28)$. Early eggs uniformly white; length 1.1-1.2 $\mathrm{mm}$; later turning dark yellow and larger, with visible larval mandibles under chorion surface, length $1.3-1.5 \mathrm{~mm}$.

First instar larva. White, almost translucent, with reddish brown ocelli and mandibles. 

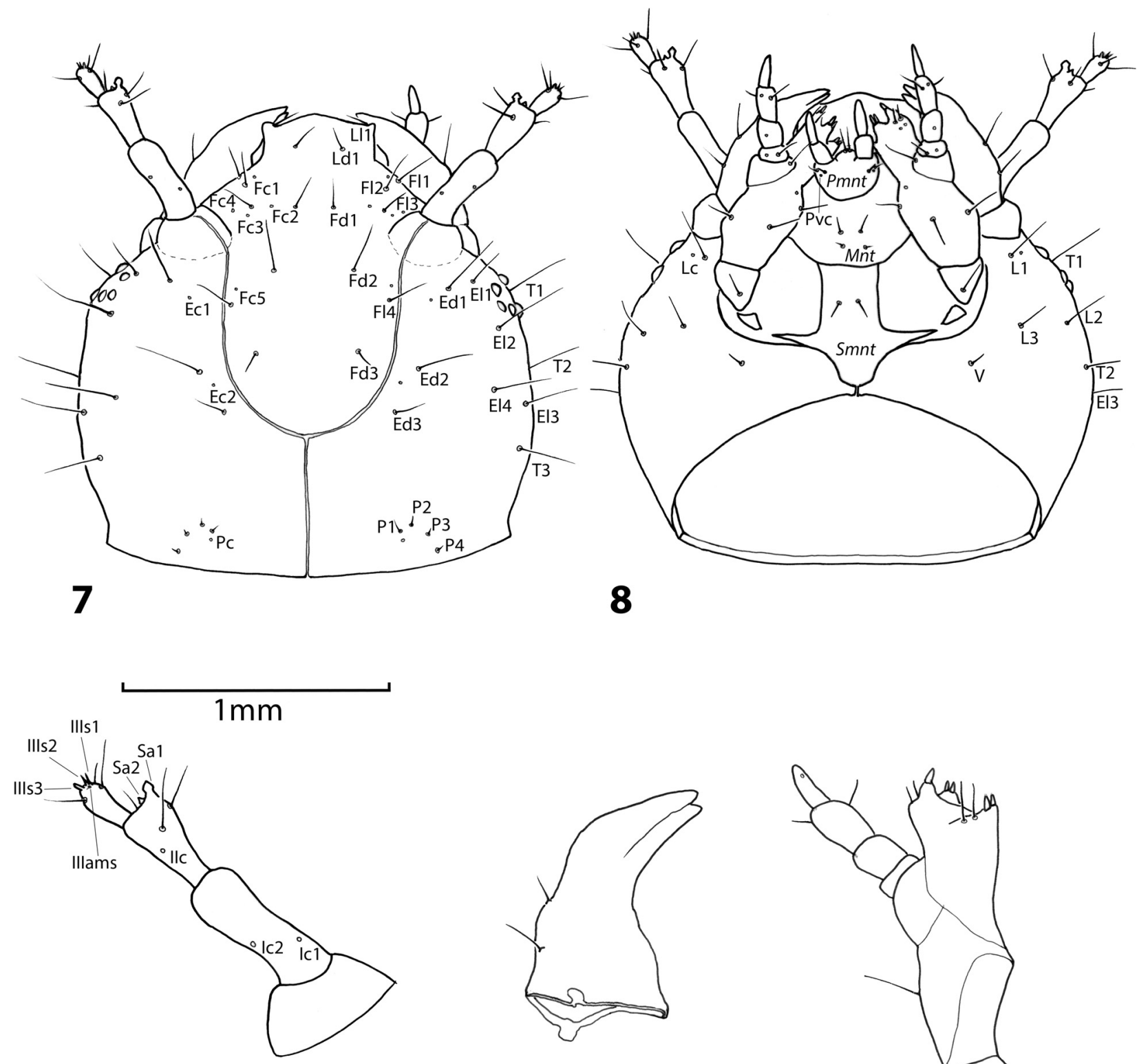

9

10

11
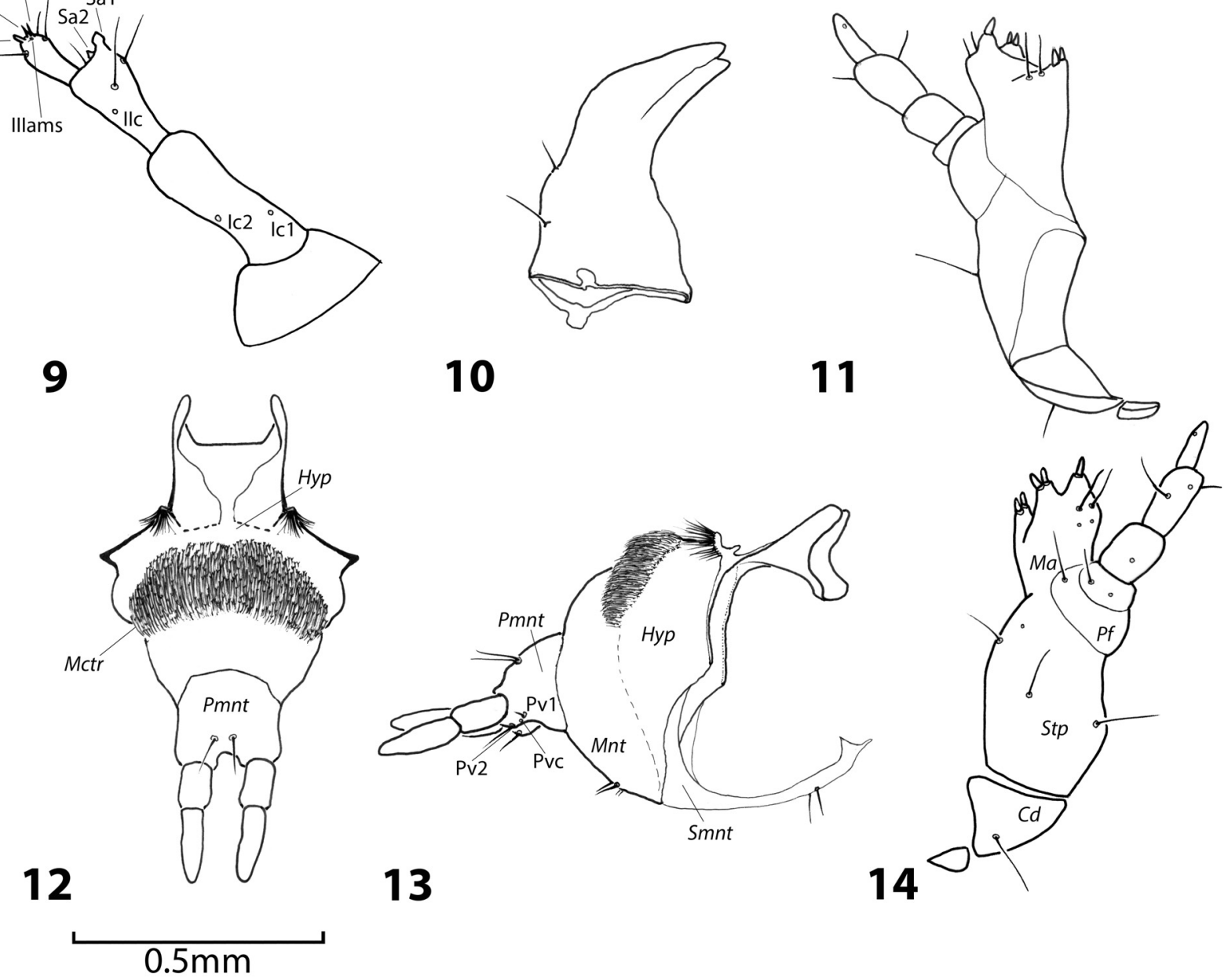

Figs 7-14. Third instar larva of Oxyporus maxillosus Fabricius, 1775, head morphology. 7 - head, dorsal view; 8 - head, ventral view; 9 - antenna, dorsal view; 10 - mandible, dorsal view; 11 - maxilla, dorsal view; 12 - labium, dorsal view; 13 - labium, lateral view; 14 - maxilla, ventral view. 

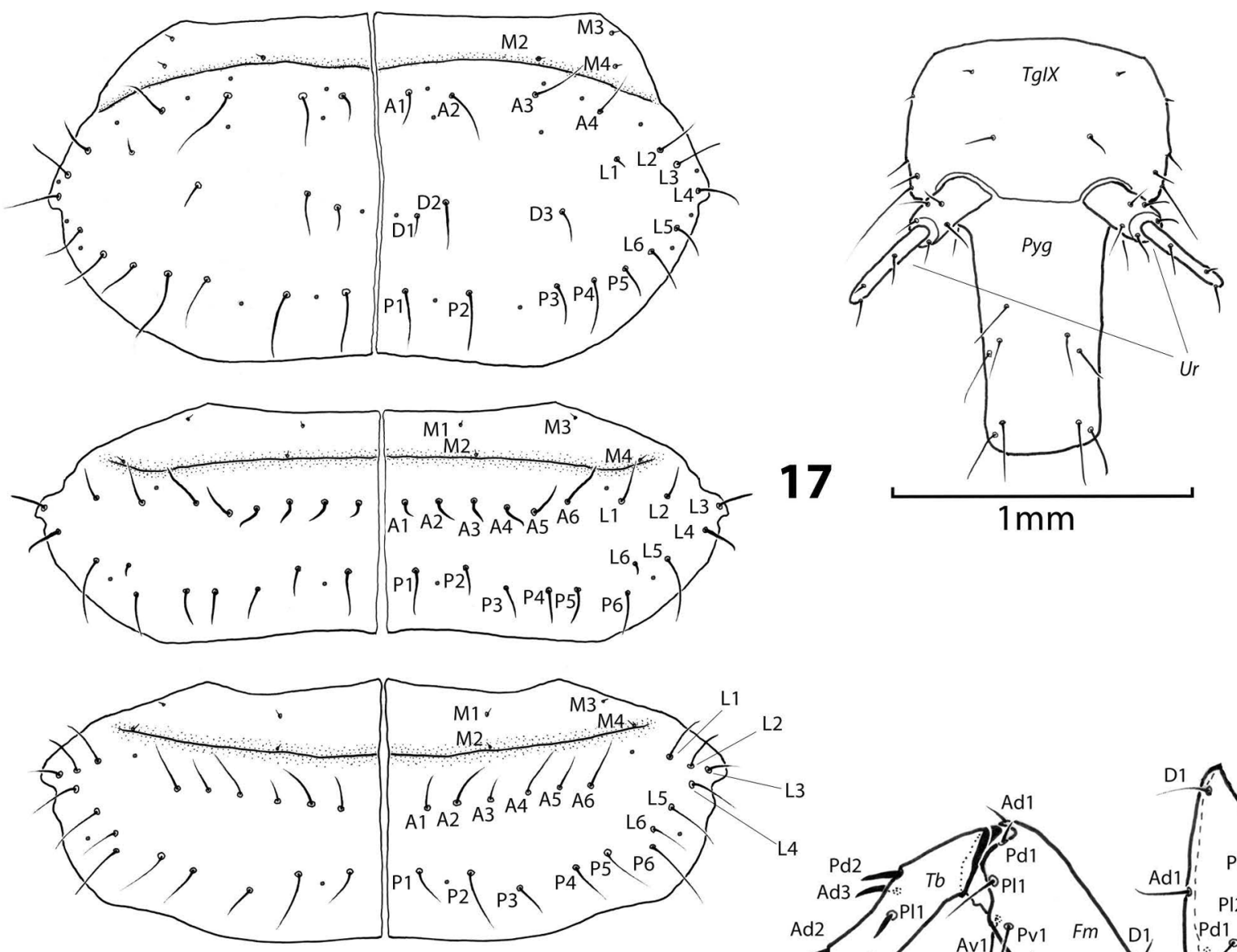

15

\section{6}

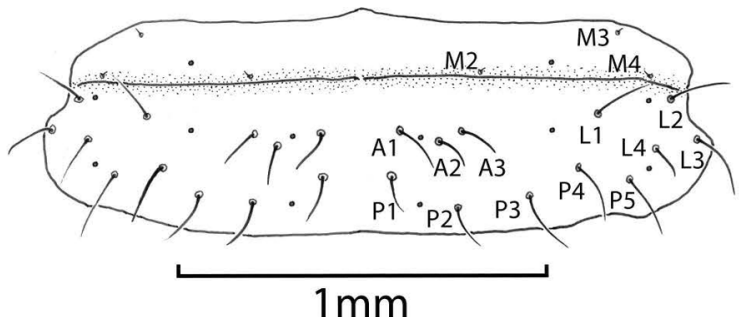

12

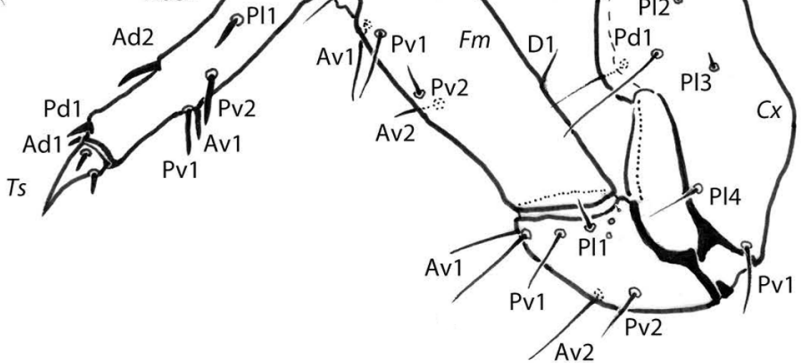

18

$1 \mathrm{~mm}$

Figs 15-18. Third instar larva of Oxyporus maxillosus Fabricius, 1775, selected body tergites. 15 - thoracic tergites I-III; 16 - abdominal tergite I; 17 - apex of abdomen, dorsal view; 18 - mesothoracic leg, posterior view.

Third instar larva. Head capsule yellowish brown with mosaic of darkened pits arranged in series on frons and occiput; thoracic and abdominal tergites uniformly greyish brown. Body length 10.3-13.1 mm; head length: $1.2-1.5 \mathrm{~mm}$; head width: $1.3-1.4 \mathrm{~mm}$.

Head. Oval, broadened at base (Figs 7,8). Nasale with two pairs of setae of medium length $(L l 1, L d 1)$ on dorsal surface. Frontal setae arranged in vertical rows $F d 1-F d 3$ and Fll-Fl4. Occipital group consists of microsetae $P 1-P 4$ and one campaniform sensillum. Epicranial setae arranged in rows on each side: $E d 1-E d 3, E l 1-E l 4, T 1-T 3$, L1-L3, V1. Head capsule with 52 setae in total. Campaniform sensilla (c. s.) present on head capsule: $F c 1-F c 5$, Ec1, Ec2, Pc (Figs 22, 23), Lc (Fig. 24). Antennomere I with two campaniform sensilla dorsally $(I c 1, I c 2)$ in basal portion and two ventrally (Ic3, Ic4) in apical portion (Fig.
8). Mandibles with two setae on outer side. Maxillary palpi with palpifer as in general description; palpomere II with two setae and one campaniform sensillum. Labium as in general description; prementum with two setae and a campaniform sensilum at the base of each labial palp: $P v 1, P v 2, P c$ (Figs 9-14).

Thorax. Membrane anterior to pronotum with three pairs of microsetae (M2, M3, M4 as interpreted in Goodrich \& Hanley 1995 for mesonotum and metanotum: figs 9A, B, C). Pronotal tergite with anterior, discoidal, lateral, and posterior rows $A 1-A 4, D 1-D 3$, L1-L6 and P1-P5. Membrane anterior to mesonotum with four pairs of microsetae $M 1, M 2, M 3, M 4$. Mesonotum with anterior, lateral, and posterior (A1-A6, L1-L6, $P 1-P 6)$ setae. Metanotum with setation as on mesonotum (Fig. 15). 

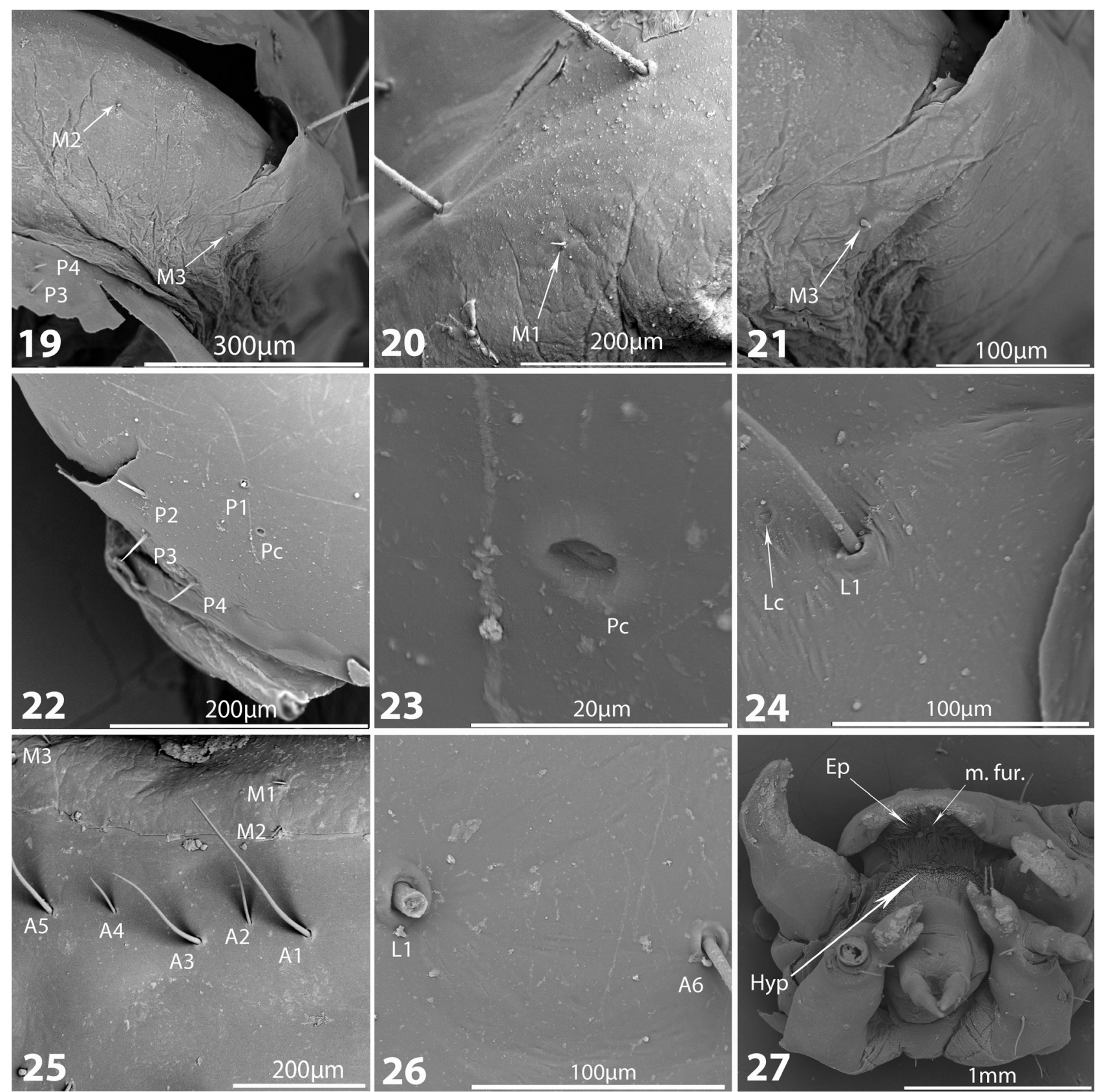

Figs 19-27. Scanning electron micrographs of larva of Oxyporus maxillosus Fabricius, 1775. 19 - cervical intersegmental membrane with microsetae M2, M3; 20 - M1 microseta, magnified; 21 - M3 microseta, magnified; 22 - posterior epicranial group of sensilla; 23 - posterior epicranial campaniform sensillum; 24 - ventral sensilla, head capsule; 25, 26 - campaniform sensilla missing between mesonotal setae; 27 - epipharynx with median furrow, hypopharynx with microtrichia.

Legs. Tarsungulus with two spine-shaped, short setae. Tibiotarsus with five spine-shaped, short setae on dorsal side, two on lateral side, and three on ventral side, nine setae in total. Femur with three setae on ventral side, two on lateral side, three on dorsal side, eight setae in total. Trochanter with three setae near $T r-F e$ joint of which medial seta twice as long as each neighboring seta, two setae medially, one short thin seta near coxal joint on each lateral side, and one short thin seta near $C x-T r$ joint dorsally, in total eight setae. Coxa with 18 setae, including several basal microsetae (Fig. 18).

Abdomen. Membrane anterior to abdominal tergite I with three pairs of microsetae (M2-M4). Abdominal tergite I with anterior, lateral, and posterior rows: $A 1-A 3$, $L 1-L 4, P 1-P 5$. Last abdominal tergite with four setae on dorsal side and three setae on each lateral side on posterior angles. Urogomphi as in generic description. Pygopod with asymmetrically arranged 18 setae (Figs 16, 17).

Development. According to Scheerpeltz \& HöFler (1948) who described the development of the European O. maxillosus reared from the cluster of 30 eggs found in Pholiota lucifera (Lasch) Quél. at room temperature in laboratory, the life cycle takes 15 days from egg to the third moult (i.e. the moult to pupa). They provided the following data for the duration of each stage: egg: 48 hours; instar I: 4 days, instar II: 5 days; instar III: 5 


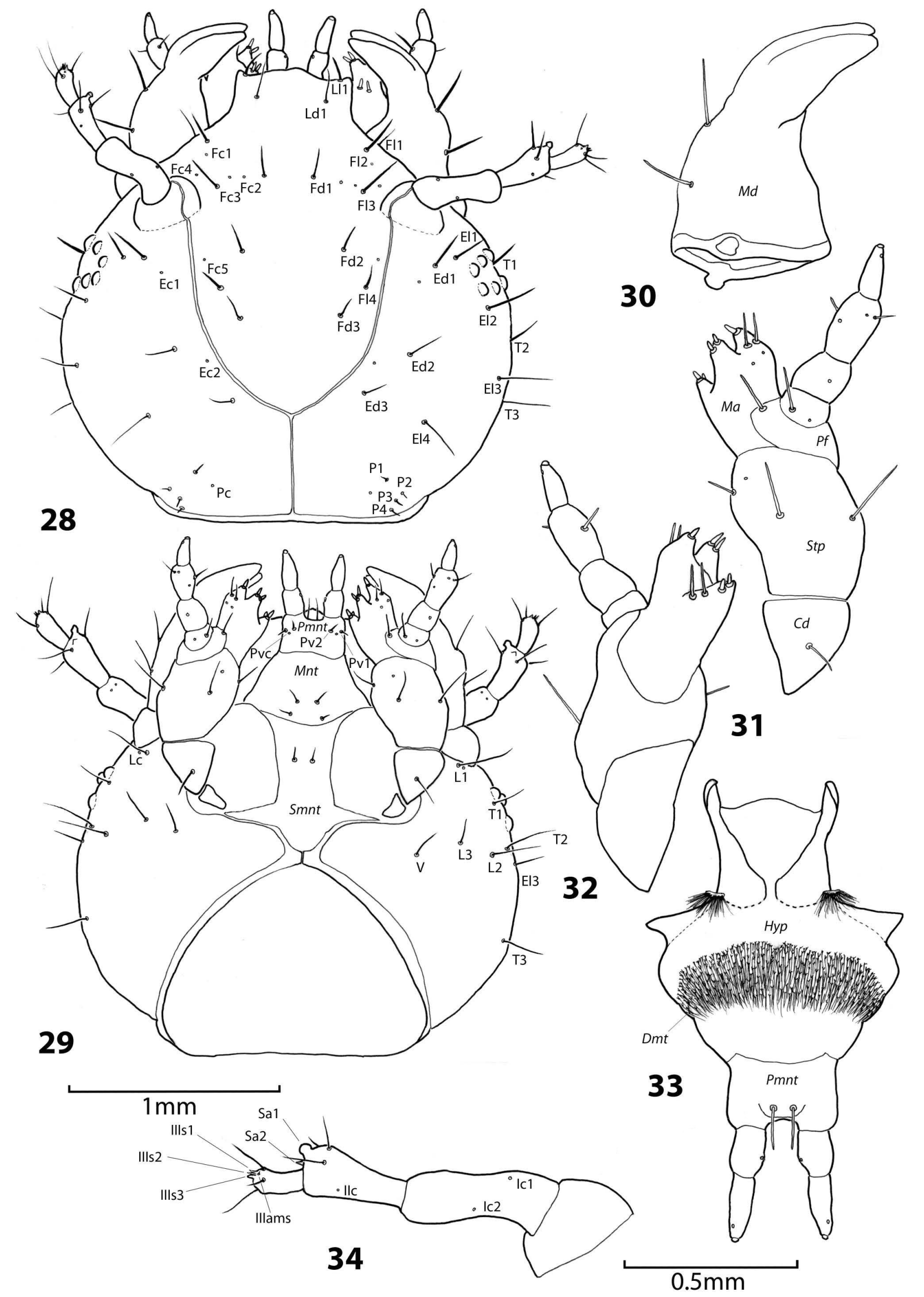

Figs 28-34. Third instar larva of Oxyporus procerus Kraatz, 1879, head morphology. 28 - head, dorsal view; 29 - head, ventral view; 30 - mandible, dorsal view; 31 - maxilla, ventral view; 32 - maxilla, dorsal view; 33 - labium, dorsal view; 34 - antenna, dorsal view. 
days. Our field data show three larval instars as well and the life cycle taking 11-12 days from egg to imago (egg: 5-6 hours; instar I: 1-2 days, from instar II through instar III to prepupa: 6 days; prepupa: 1 day; pupa: 6-7 days). Duration of the second and third larval instars is unknown. Observed host fungi of larvae. Cortinariaceae: Cortinarius sp.; Physalacriaceae: Armillaria sp.; Strophariaceae: Pholiota sp.; Suillaceae: Suillus americanus (Peck) Snell. Observed host fungi for adults. Boletaceae: Leccinum holopus (Rostk.) Watling; Cortinariaceae: Cortinarius sp.; Physalacriaceae: Armillaria sp.; Fomitopsidaceae: Laetiporus sp.; Strophariaceae: Kuechneromyces sp., Pholiota aurivella (Batsch) P. Kumm., Pholiota sp.; Pleurotaceae: Pleurotus ostreatus (Jacq.) P. Kumm., Pleurotus pulmonarius (Fr.) Quél.; Suillaceae: Suillus americanus (Peck) Snell, Suillus sp.

Biology observations. Larvae were reared from eggs collected from chambers in the fruit body of Armillaria sp. with a female which presumably laid them. According to our observations, usually many individuals live together in a bracket of fungi like Pholiota sp., where one to three females can simultaneously be found in one cap where they are guarding their eggs in their respective chambers. Every female builds a chamber with a channel inside the cap. Each chamber may contain 10-31 eggs. Sometimes one female builds two chambers with e.g. four and six eggs in each. Mothers remain in a chamber with their eggs or first instar larvae until the latter moult to the second instar and start moving out from the chambers, tunneling through the fungal fruit body. Presumably they do so to protect their brood from predatory myriapods, Bolitobius (Staphylinidae) species and other Oxyporus females, which compete for the room, as earlier suggested by Setsuda (1994). Upon moulting into the third instar, larvae become pink, and shortly after they stop feeding and start to dig into the soil for pupation. Once a larva stops digging, it makes a pupation chamber, where it soon becomes quiescent until moulting into the adult (prepupal stage). Usually one or two females of $O$. basiventris Jarrige, 1948 or $O$. aokii Dvořák, 1956 were found in the same fungal bodies with $O$. maxillosus during field observations in Russian Far East.

\section{Oxyporus (Oxyporus) procerus Kraatz, 1879} (Figs 2, 28-44)

Material examined. 13 third instar larvae (NHMD): RUSSIA: PrIMoRSKY Territory: Arboretum of the Gornotaezhnaya Station FEB RAS, $43.6945498^{\circ} \mathrm{N}, 132.1520375^{\circ} \mathrm{E}, 10.1 x .2018$, from Pleurotus sp., A. Tokareva leg. 13 third instar larvae were reared by A. Tokareva (rearing R13) from second instar larvae collected in the fungus.

DNA barcoding. 1 third instar larva (NHMD620700: GenBank Accession No.: MN508940) and one associated adult (NHMD620701: GenBank Accession No: MN508941).

Diagnosis. Oxyporus procerus larva differs from any other described Oxyporus larvae including $O$. maxillosus and $O$. (P.) melanocephalus by the following characters: thoracic tergite I with six anterior setae $(A 1-A 6)$; color pattern with brownish yellow head capsule and yellow tergites; body twice or more times as big as that described for other Oxyporus larvae. Larva of O. procerus further
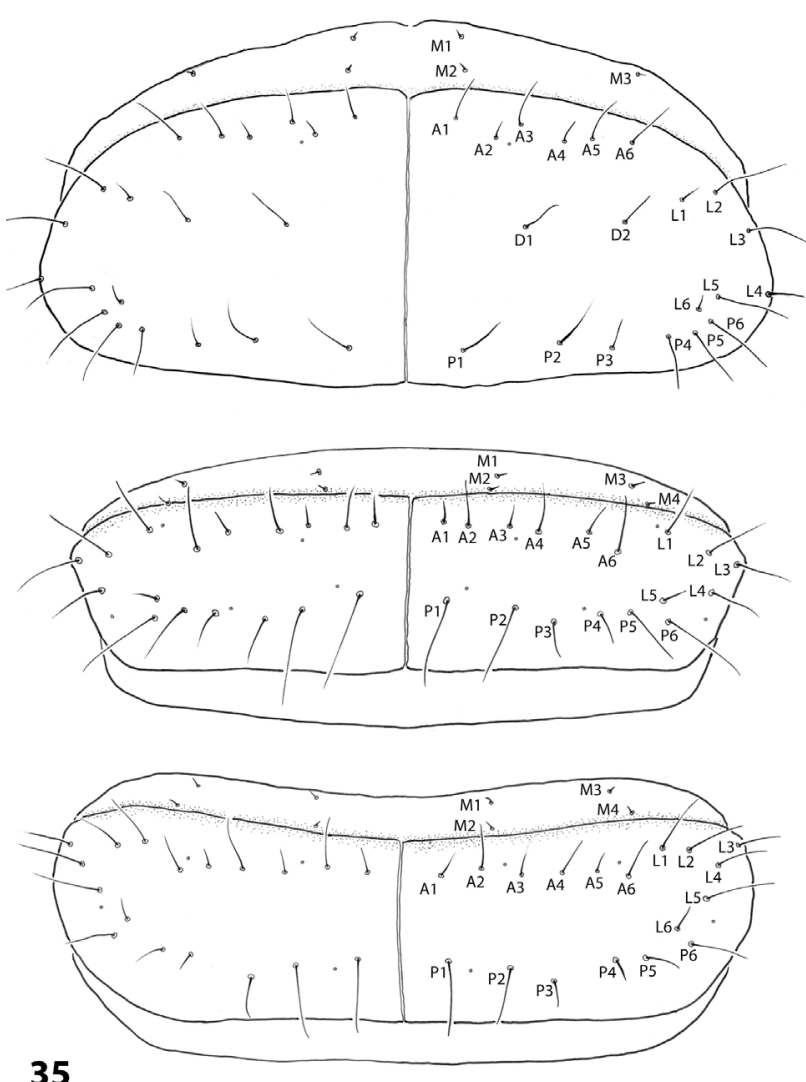

35

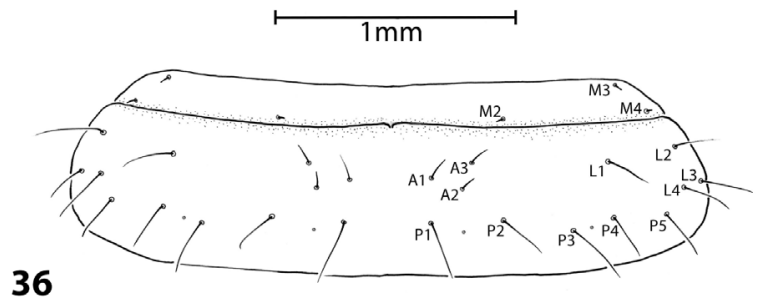

Figs 35-36. Third instar larva of Oxyporus procerus Kraatz, 1879, selected body tergites. 35 - thoracic tergites I-III; 36 - abdominal tergite I.

differs from that of $O$. maxillosus by the following characters: three membrane setae on each side before thoracic tergite I (M1-M3); six anterior setae $(A 1-A 6)$ and six posterior setae $(P 1-P 6)$ on each side of thoracic tergite I, five lateral setae $(L 1-L 5)$ on each side of thoracic tergite II). Description. Head capsule brownish yellow, thoracic and abdominal tergites yellow; body length 16.8-20.9 mm; head length 1.9-2.1 mm; head width 1.9-2.05 mm; $\mathrm{n}=13$.

Head. Oval to slightly drop-shaped (Figs 28, 29). Nasale with two pairs of setae of medium length ( $L l 1$, $L d 1$ ) on dorsal surface and four short setae on anterior margin $(L m 1, L m 2)$. Frontal setae arranged in vertical rows $F d 1-F d 3$ and $F l 1-F l 4$. Occipital group consists of microsetae $P 1-P 4$ and one campaniform sensillum. Epicranial setae arranged in rows on each side: $E d 1-E d 3$, El1-El4, T1-T3, L1-L3, V1. Head capsule with 52 setae in total. Campaniform sensilla present on head capsule as follows: $F c 1-F c 4, E c 1, E c 2, P c, L c$. Antennomere I with two campaniform sensilla dorsally $(I c 1, I c 2)$ in basal portion and two ventrally $(I c 3, I c 4)$ in apical portion (Fig. 


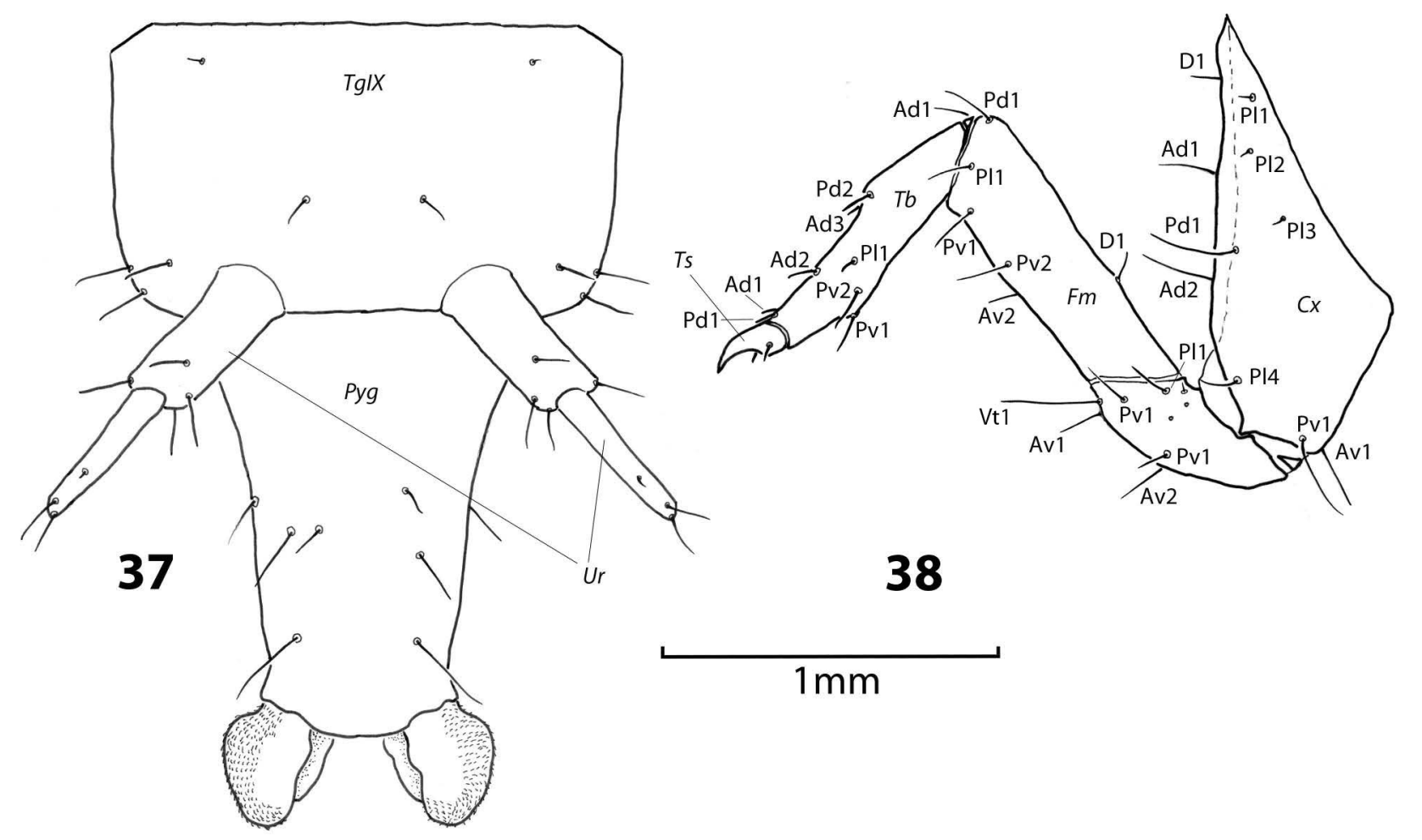

Figs 37-38. Third instar larva of Oxyporus procerus Kraatz, 1879, apex of abdomen, mesothoracic leg. 37 - apex of abdomen, dorsal view; 38 - mesothoracic leg, posterior view.

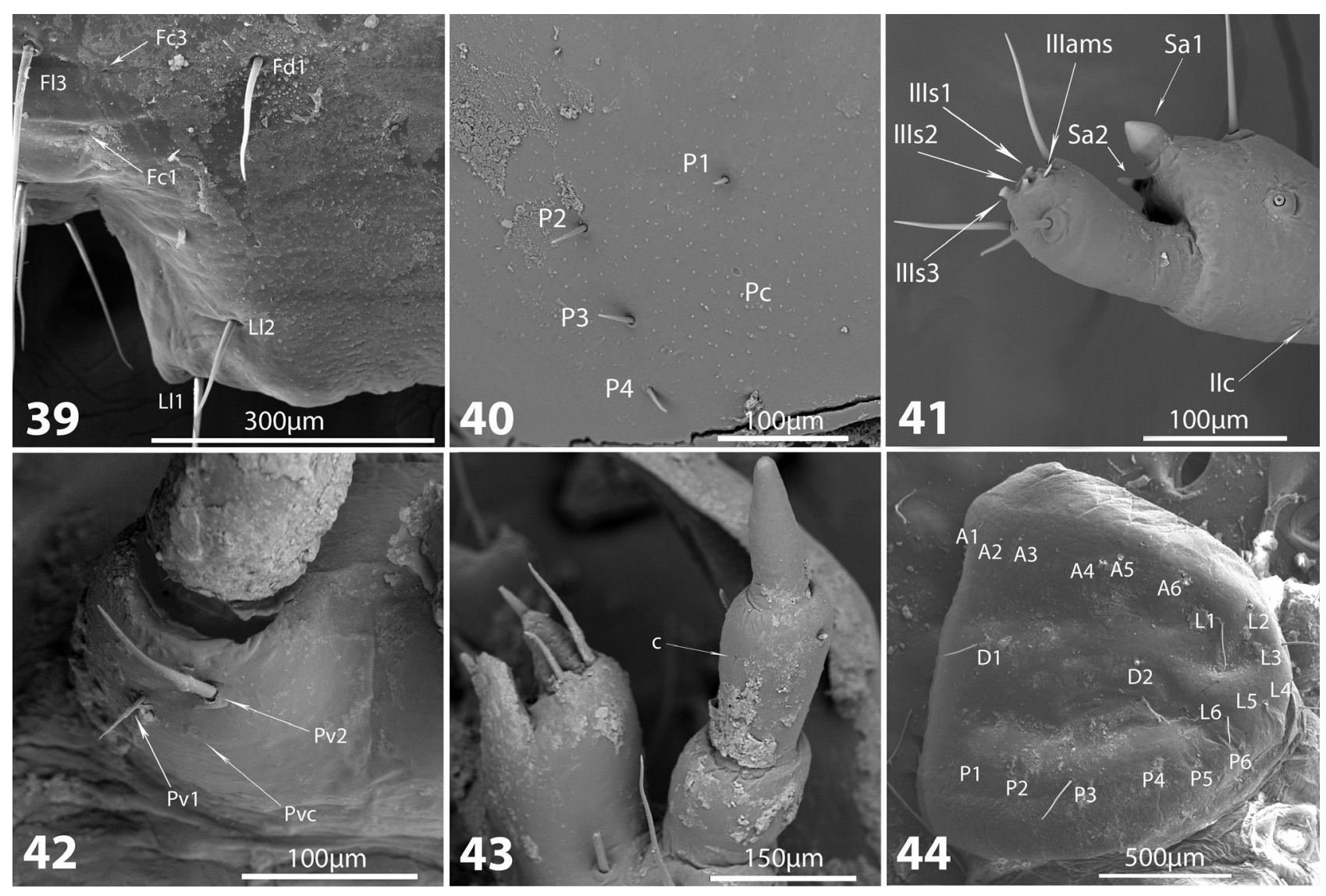

Figs 39-44. Scanning electron micrographs of larva of Oxyporus procerus Kraatz, 1879. 39 - campaniform sensilla and setae of nasale; 40 - posterior epicranial group of sensilla; 41 - antennomeres II and III, apical sensorial complex; 42 - premental group of sensilla; 43 - campaniform sensillum, segment II of maxillary palpus; 44 - thoracic tergite I, lateral view. 
29). Antennomere II with one campaniform sensillum dorsally, three setae near apex, tubercle-like (SAI) and narrow conical $(S A 2)$ sensory appendages ventrally at apex. Antennomere III with three apical setae and superior group of small sensilla consisting of one thickened membranous solenidium (IIIS3), two narrow spiny solenidia (IIIs1-IIIs2), and one microseta (IIIams) (Figs 34, 41). Mandibles with two setae on outer side. Maxillae as in general description. Maxillary palpi with palpifer as in general description. Labium as in general description; prementum with two setae and campaniform sensilla $P v 1$, $P v 2, P c$; labial palpi with one campaniform sensillum on each palpomere.

Thorax. Membrane anterior to pronotum with three pairs of microsetae $M 1, M 2, M 3$ (Fig. 20). Pronotum tergite with anterior, discoidal, lateral, and posterior rows $A 1-A 6, D 1-D 3, L 1-L 6$ and P1-P6. Membrane anterior to mesonotum with four pairs of microsetae $M 1, M 2$, M3, M4. Mesonotum with anterior, lateral, and posterior A1-A6, L1-L5, P1-P6 setae. Metanotum with setation almost as on mesonotum, except six lateral setae on each side (L1-L6) (Fig 35).

Legs. Tarsungulus with two spine-shaped, short setae. Tibiotarsus with five spine-shaped, short setae on dorsal side, two setae on lateral side, and three setae on ventral side, nine setae in total. Femur with three setae on ventral side, two on lateral side, three on dorsal side, eight setae in total. Trochanter with three setae near $\mathrm{Tr}-\mathrm{Fe}$ joint of which medial seta twice as long as each neighbour seta, two setae more medially, one short thin seta near coxal joint on each lateral side, and one short thin seta near $C x-\operatorname{Tr}$ joint dorsally, in total eight setae. Coxa with 18 setae, including several basal microsetae (Fig. 38).

Abdomen. Membrane anterior to abdominal tergite I with three pairs of setae (M2-M4) and one pls. Abdominal tergite I with anterior, lateral, and posterior rows: $A 1-A 3$, $L 1-L 4, P 1-P 5$. Last abdominal tergite with two pairs of setae on dorsal side and three setae on each lateral side on posterior angles. Urogomphi as in generic description. Pygopod with asymmetrically arranged 16-18 setae (Figs 36, 37).

Development. The life cycle duration was observed only from the third instar which took 5 days until the prepupal stage.

Observed host fungi for larvae. Pleurotaceae: Pleurotus sp.

Observed host fungi for adults. Pleurotaceae: Pleurotus sp., Fomitopsidaceae: Laetiporus sulphureus (Bull.) Murrill.

Biology observations. According to our observations single females were often found with $O$. maxillosus feeding on Laetiporus sulphureus but no larvae of $O x y$ porus were ever found in this fungal species. Mature third instar larvae turn pink and migrate for pupation in soil. According to observations by S. A. Shabalin (pers. comm.), this species (adults and larvae) usually feeds on different Pleurotus species on fallen lime trees (Tilia sp.) and alder trees (Alnus sp.) along small streams and thus can be found mostly in September or later.

\section{Subgenus Pseudoxyporus Nakane \& Sawada, 1956}

\section{Oxyporus (Pseudoxyporus) melanocephalus Kirshenblat, 1938 \\ (Figs 3, 5, 6, 45-62)}

Material examined. 10 third instar larvae (NHMD): RUSSIA: PrIMORSKY TERRITORY: Arboretum of the Gornotaezhnaya Station FEB RAS, $43.6945498^{\circ} \mathrm{N}, 132.1520375^{\circ} \mathrm{E}, 11.1 x .2018$, from Pholiota sp., A. Tokareva leg. 10 third instar larvae were reared by A. Tokareva (rearing R13) from eggs to third instar larvae collected in the fungus.

DNA bardcoding. 1 third instar larva (NHMD620698: GenBank Accession No.: MN508939) and one associated adult (NHMD620699: GenBank Accession No: MN508938).

Diagnosis. Larva of $O$. melanocephalus differs from other described Oxyporus larvae by the following set of chaetotaxy characters: two $D$ setae on thoracic tergite I, three $A$ and three $P$ setae on thoracic tergite II, three $A$, five $L$, and three $P$ on thoracic tergite III. It differs from larvae of both $O$. procerus and $O$. maxillosus by two lateral $(L c 1-L c 2)$ and one ventral campaniform sensilla $(V c)$ on each side of head capsule; dorsal c. s. on mala located between two lateral setae above medial seta and under palpifer (compare Fig. 52 with Figs 14, 31); five anterior $(A 1-A 5)$, two discoidal $(D 1-D 2)$, and five lateral setae $(L 1-L 5)$ on each side of thoracic tergite I; three anterior setae $(A 1-A 3)$, three posterior setae $(P 1-P 3)$ on each side of thoracic tergite II; three membrane setae $(M 1-M 3)$ on each side before thoracic tergite III; three anterior setae $(A 1-A 3)$, five lateral setae $(L 1-L 5)$, three posterior setae $(P 1-P 3)$ on each side of thoracic tergite III; two anterior setae $(A 1-A 2)$, five lateral setae $(L 1-L 5)$, three posterior setae $(P 1-P 3)$ on each side of abdominal tergite I.

Description. Tergites pale yellow, head capsule yellow. Third instar body length: 9.6-12.6 mm; head length: 1.1-1.3 mm; head width: $1.2-1.4 \mathrm{~mm} ; \mathrm{n}=10$.

Head. Oval (Figs 45-46). Nasale with two pairs of setae of average length $(L l 1, L d 1)$. Frontal setae in vertical rows $F d 1-F d 3$ and $F l 1-F l 4$. Occipital group consists of microsetae $P 1-P 4$ and one campaniform sensillum. Epicranial setae arranged in rows on each side: $E d 1-E d 3$, El1-El4, T1-T3, L1-L3, V1. Head capsule with 52 setae in total. Campaniform sensilla present on head capsule: $F c 1-F c 5, E c 1, E c 2, P c, L c 1, L c 2, V c$. Antennomere I with two campaniform sensilla dorsally $(I c 1, I c 2)$ in basal portion and two ventrally (Ic3, Ic4) in apical portion (Fig. 29). Antennomere II with one campaniform sensillum dorsally, three setae near apex, tubercle-like (SA1) and narrow conical (SA2) sensory appendages ventrally at apex. Antennomere III with three apical setae and superior group of small sensilla consisting of one thickened membranous solenidium (IIIs 3 ), two narrow spiny solenidia (IIIs 1-IIIs 2), and one microseta (IIIams) (Fig. 47). Mandibles with two setae on outer side. Maxillae as in general description. Maxillary palpi with palpifer as in general description. Labium as in general description; labial apex distinct, ligula-like, with two setae and half-ring of microtrichia ventrally on hypopharyngeal part; prementum with two setae and campaniform sensilla, $P v 1$, $P v 2, P c$; labial palpus with one campaniform sensillum on each palpomere (Figs 47-52). 


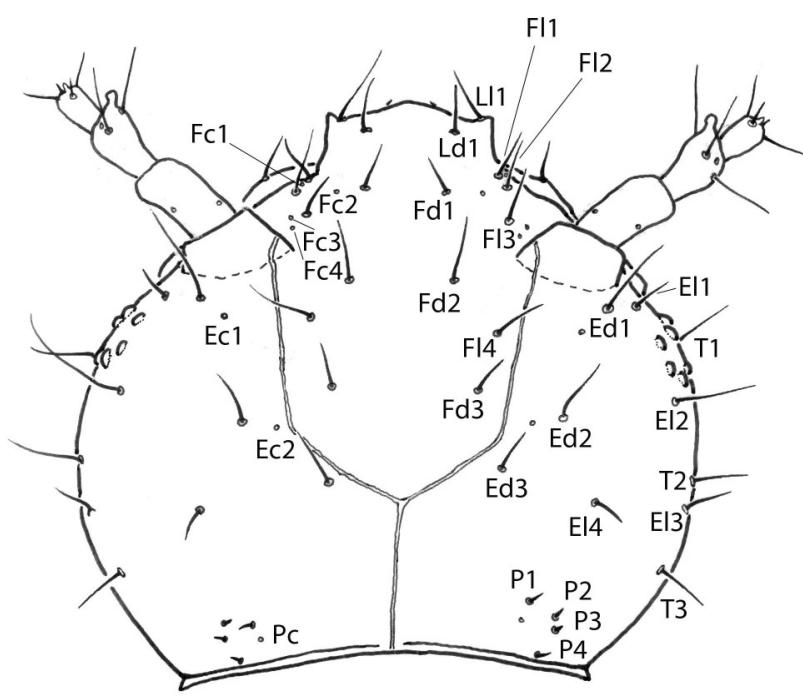

45

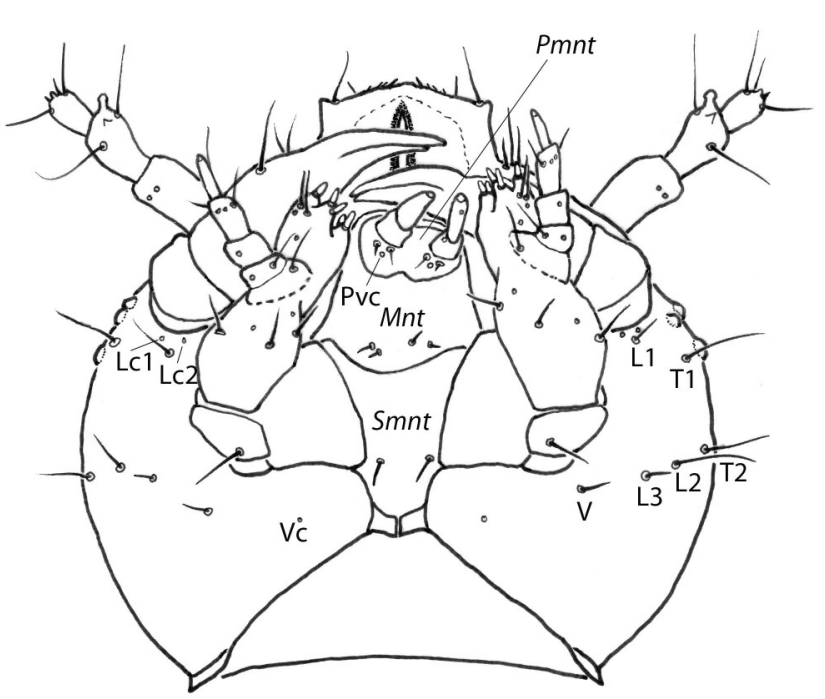

46

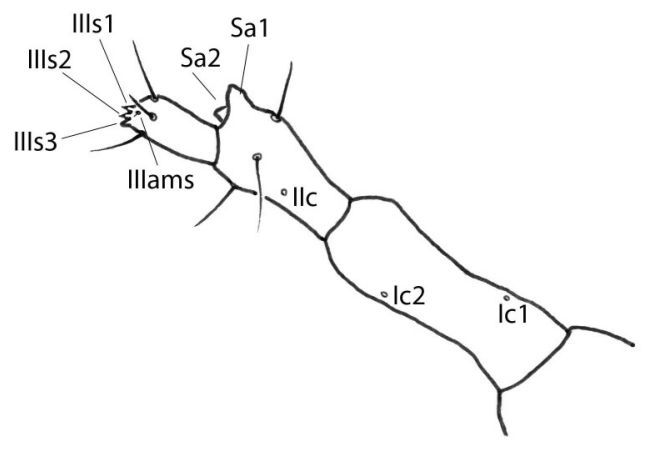

47

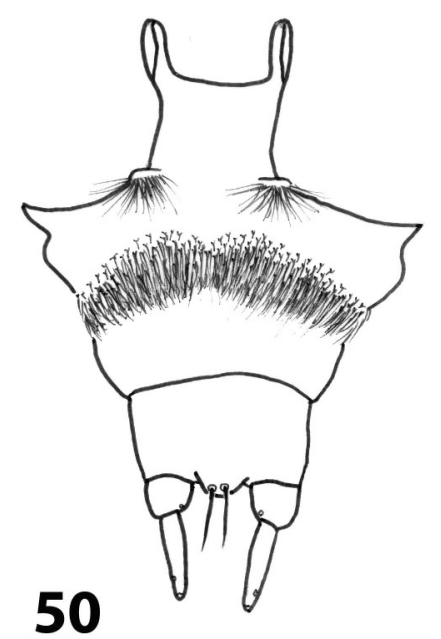

51
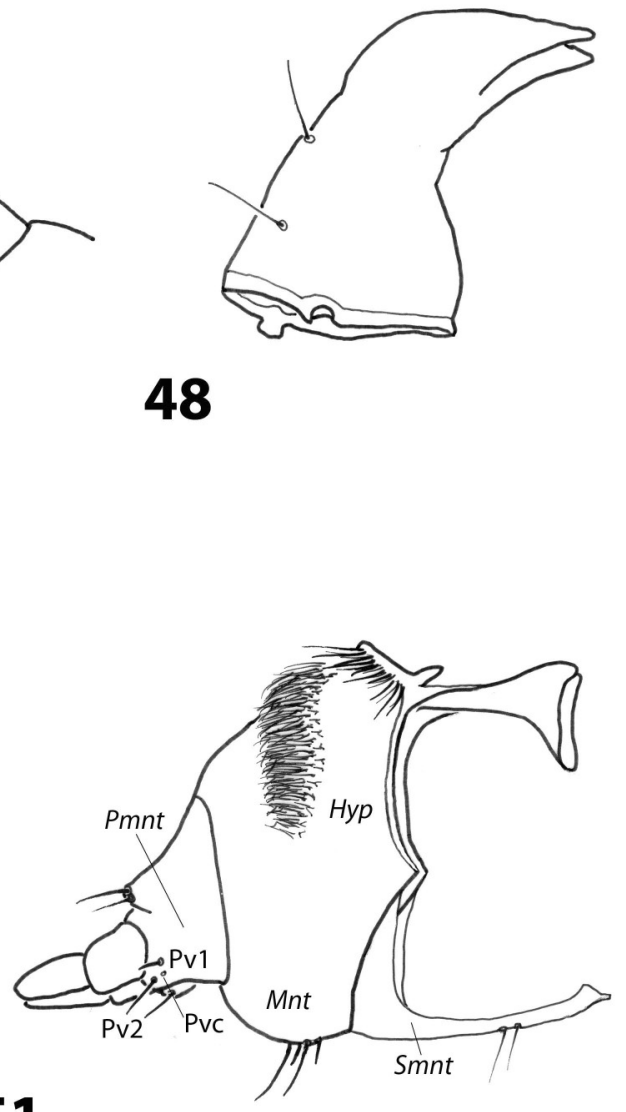

48

49

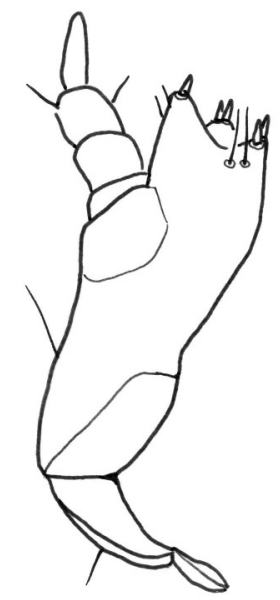

52

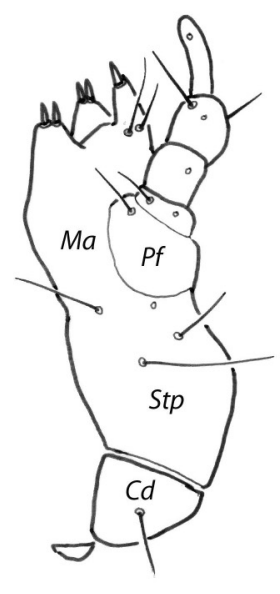

\section{$0.5 \mathrm{~mm}$}

Figs 45-52. Third instar larva of Oxyporus (P.) melanocephalus Kirschenblatt, 1938, head morphology. 45 - head, dorsal view; 46 - head, ventral view; 47 - antenna, dorsal view; 48 - mandible, dorsal view; 49 - maxilla, dorsal view; 50 - labium, dorsal view; 51 - labium, lateral view; 52 - maxilla, ventral view. 

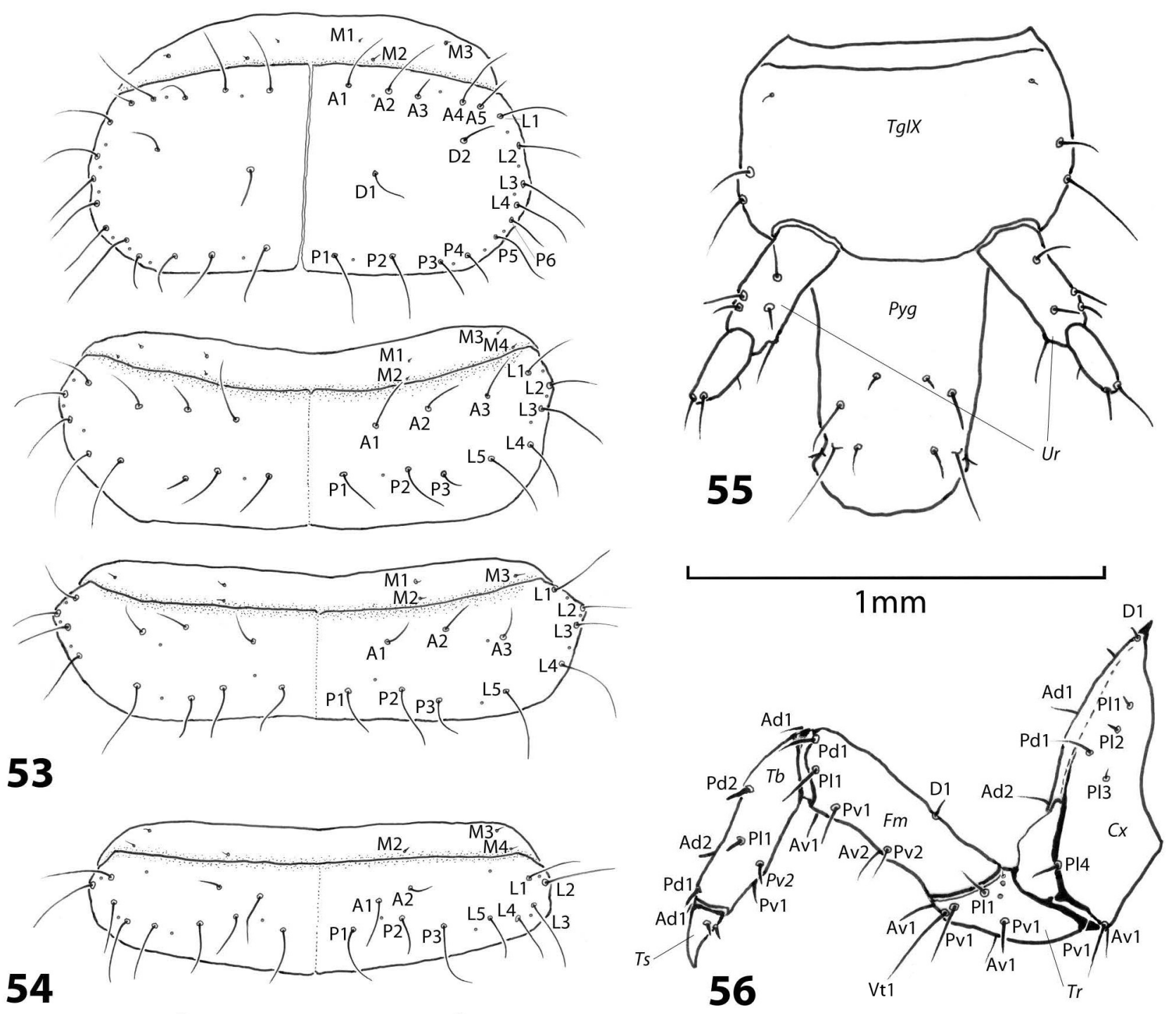

54

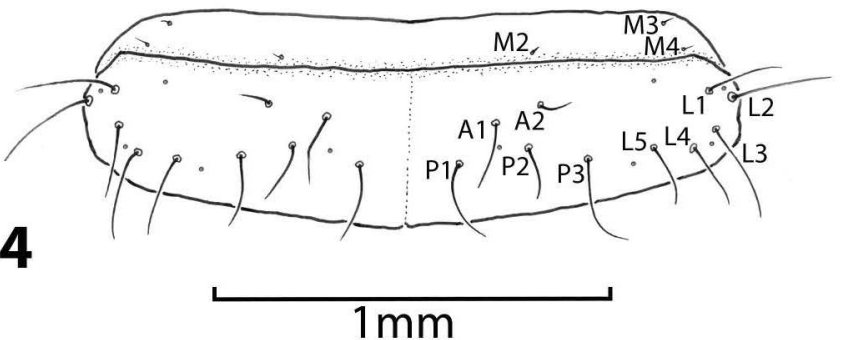

56

$\mathrm{Vt} 1$

Figs 53-56. Third instar larva of Oxyporus (P.) melanocephalus Kirschenblatt, 1938, selected body tergites. 53 - thoracic tergites I-III; 54 - abdominal tergite I; 55 - abdominal apex, dorsal view; 56 - mesothoracic leg, posterior view.

Thorax. Membrane anterior to pronotum with three pairs of microsetae $M 1, M 2, M 3$ (Figs 53, 58). Pronotum tergite with anterior, discoidal, lateral and posterior rows A1-A5, D1-D2, L1-L5 and P1-P6. Membrane anterior to mesonotum with four pairs of microsetae $M 1, M 2, M 3$, $M 4$. Mesonotum with anterior, lateral, and posterior ( $A 1-$ $A 3, L 1-L 5, P 1-P 3)$ setae. Metanotum with setation as on mesonotum (Fig. 53).

Legs. Tarsungulus with two spine-shaped, short setae. Tibiotarsus with five spine-shaped short setae on dorsal side, two setae on lateral side, and three on ventral side, nine setae in total. Femur with three setae on ventral side, two on lateral side, three on dorsal side, eight setae in total. Trochanter with three setae near $\mathrm{Tr}-\mathrm{Fe}$ joint of which medial seta twice as long as each neighbouring seta, two setae more medially, one short thin seta near coxal joint on each lateral side, and one short thin seta near $C x-T r$ joint dorsally, in total eight setae. Coxa with 18 setae, including several basal microsetae (Fig. 56).
Abdomen. Membrane anterior to abdominal tergite I with three pairs of setae (M2-M4). Abdominal tergite I with anterior, lateral, and posterior rows (A $1-A 2, L 1-L 5$, $P 1-P 3)$. Last abdominal tergite with two pairs of setae on dorsal side and three setae on each lateral side on posterior angles. Urogomphi as in generic description. Pygopod with asymmetrically arranged 22 setae (Figs 54, 55).

Development. The life cycle takes 22-23 days from eggs to prepupa in the laboratory. Duration of the pupa is unknown. Observed host fungi for larvae. Strophariaceae: Pholiota sp.

Biology observations. We observed only one breed associated with one female. That female did not build a chamber but instead laid every egg separately deep between fungal gills (Fig. 66). No subsocial behavior was observed. Hatched larvae start feeding by boring thin tunnels behind the hymenophore. Because of that, and since the female made no big holes in the fungal cap, the populated fruit body looked intact externally. 


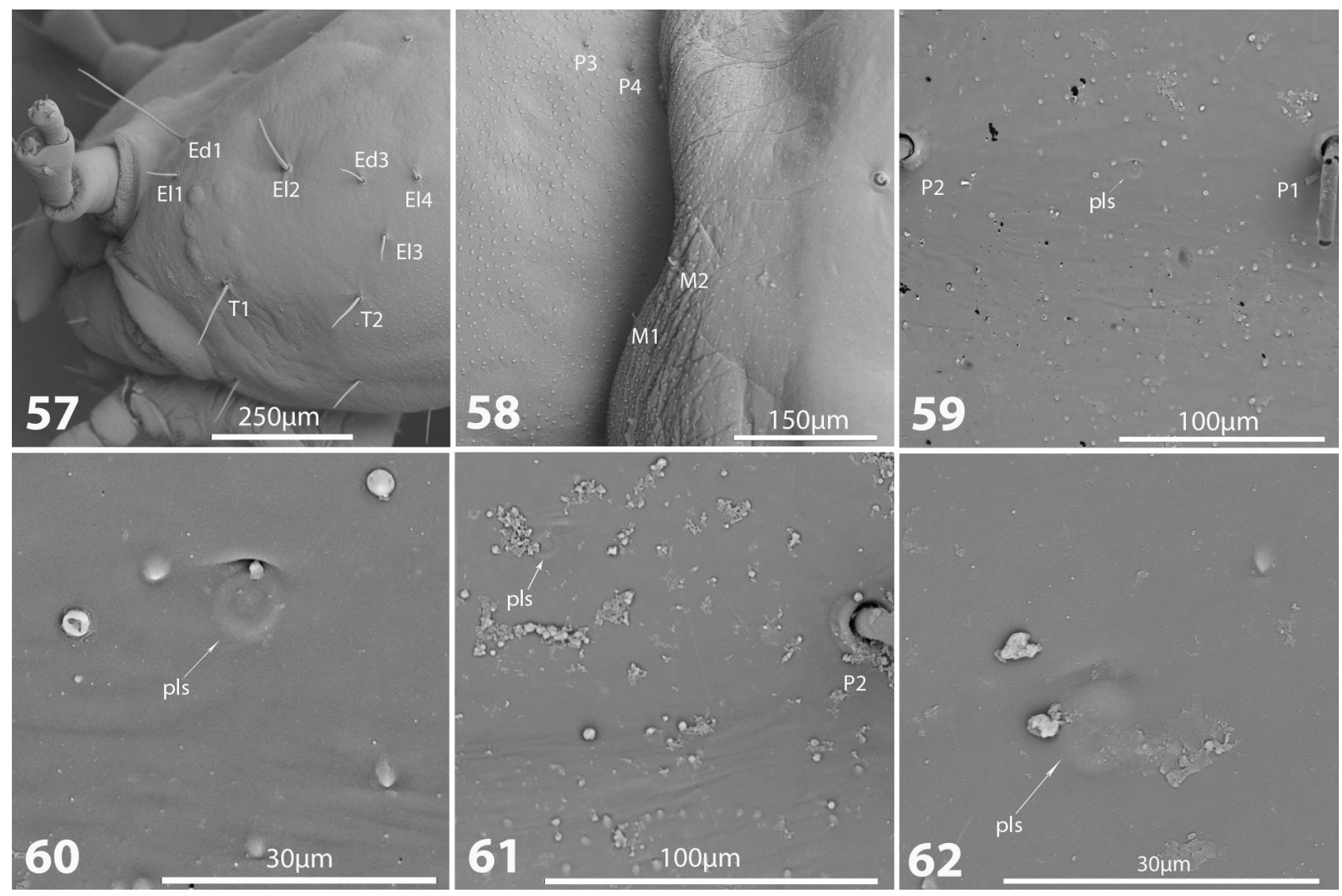

Figs 57-62. Scanning electron micrographs of larva of Oxyporus (P.) melanocephalus Kirschenblatt, 1938. 57 - head, lateral; 58 - intersegmental membrane, M1, M2 microsetae of thoracic tergite I; 59 - pore-like structure between P1-P2 pronotal setae, campaniform sensilla missing between setae; 60 - pore-like structure, magnified; 61 - pore-like structure between P1-P2 pronotal setae; 62 - pore-like structure between P1-P2 mesonotal setae.

\section{Earlier published data on Oxyporus immatures}

Here we give individual brief summaries about the life stages duration, morphological characters (everything that is known from descriptions), larval chaetotaxy formulas for some species, and some aspects of biology, as well as known distribution, for each of the nine species of Oxyporus with the published data. Larval and adult host fungi are listed separately in Table 4. However, the table includes only those fungal hosts for adults that were mentioned in publications on immature stages of Oxyporus.

\section{Subgenus Oxyporus s. str.}

\section{Oxyporus (Oxyporus) femoralis Gravenhorst, 1802}

Published data. Campbell (1969): biology; LesChen \& Allen (1988): description of L1, L3, biology.

Larval morphology. Distinguished from other described Oxyporus larvae by the darkly pigmented head and sclerites; short and sublateral setae present on premental sclerite (Leschen \& Allen 1988: fig. 3G).

Development. Third instar larvae developed into adults in laboratory at room temperature in 10 days after their collection.

Adults and larvae have been collected in the north of United States (Michigan) from May to October and from July to November in the southeast (Arkansas). No beetles were collected during a drought in Arkansas in July when fungi were scarce (LESCHEN \& AlLEN, 1988).

\section{Oxyporus (Oxyporus) germanus Sharp, 1889}

Published data. Hwang et al. (2002): description of E, L3 morphology, biology and hosts.

Larval morphology. Chaetotaxy. Head: $L l ; L d ; L m 1-$ Lm2; Fd1-Fd3; Fl1-Fl4; Ed1-Ed3; El1-El4; T1-T3; L1-L2; V1; V; P1-P4. Antennae: Sa2. Labium: V1-V2; $C$. Thoracic tergite I: $A 1-A 7 ; D 1-D 3 ; L 1-L 4 ; P 1-P 6$. Thoracic tergite II: $M 1-M 6 ; A 1-A 7 ; L 1-L 5 ; P 1-P 6$. Thoracic tergite III: $M 1-M 6 ; A 1-A 7 ; L 1-L 4 ; P 1-P 6$. Abdominal tergite I: M1-M4; A1-A4; L1-L3; P1-P5. Development. Pupae developed into adults in 6-9 days $\left(22-24^{\circ} \mathrm{C}\right)$.

\section{Oxyporus (Oxyporus) japonicus Sharp, 1889}

Published data. Hanley \& Setsuda (1999): description of E, L3, P, biology and hosts; SETSUDA (1994): subsocial behavior.

Larval morphology. Distinguished from other described Oxyporus larvae by $E d 1-E d 2$ in epicranial row; $A 1-A 5$ in pronotal anterior row; $A 1-A 8$ in mesonotal anterior row.

Chaetotaxy. Head: Fd1-Fd3; Fll-Fl3; Ed1-Ed2; El1-El4; T1-T3; L1-L3; Vl1-Vl2; V1; P1-P3. Antennae: Sa1-Sa2. Labium: V1. Thoracic tergite I: $A 1-A 5 ; D 1-D 3$; L1-L3; P1-P3. Thoracic tergite II: M1-M5; A1-A8; L1- 
Table 3. Summary of chaetotaxy of Oxyporus third instar (L3) larvae described in this paper. Characters unique for each species boldfaced and underlined. Abbreviations: Head capsule. Ed - epicranial dorsal setae; Ec - epicranial campaniform sensilla; EI - epicranial lateral setae; Fd - frontal dorsal cranial setae; Fc - frontal campaniform sensilla; FI - frontal lateral cranial setae; L - lateral cranial setae; Ld - labral dorsal setae; LI - labral lateral setae; Pc - posterior cranial campaniform sensillum; T - temporal cranial setae; VI - ventrolateral cranial setae; V - ventral setae; Vc - ventral campaniform sensilla. Thoracic tergites I-III, abdominal tergite I. A1-A4 - anterior tergal setae; D1-D3 - discoidal thoracic tergal setae; $\boldsymbol{M}$ - dorsal body membrane setae; $\boldsymbol{L}$ - lateral tergal setae; $\boldsymbol{P}$ - posterior tergal setae; $\boldsymbol{P} \mathbf{1}-\boldsymbol{P 5}$ - posterior tergal setae.

\begin{tabular}{|c|c|c|c|}
\hline & $\begin{array}{l}\text { Oxyporus (s.str.) maxillosus } \\
\text { Fabricius, } 1793\end{array}$ & $\begin{array}{l}\text { Oxyporus (s.str.) procerus } \\
\text { Kraatz, } 1879\end{array}$ & $\begin{array}{l}\text { Oxyporus }(P .) \text { melanocephalus } \\
\text { Kirschenblatt, } 1938\end{array}$ \\
\hline Head capsule & $\begin{array}{l}\text { L11, Ld1; F11-F14; Fd1-Fd3; Fc1-Fc5; } \\
\text { Ed1-Ed3; E11-E14; Ec1-Ec2; T1-T2; } \\
\text { L1-L3; Lc; V; P1-P4; Pc }\end{array}$ & $\begin{array}{l}\text { L11, Ld1; F11-F14; Fd1-Fd3; Fc1-Fc5; } \\
\text { Ed1-Ed3; E11-E14; Ec1-Ec2; T1-T3; } \\
\text { L1-L3; Lc; V; P1-P4; Pc }\end{array}$ & $\begin{array}{l}\text { L11, Ld1; F11-F14; Fd1-Fd3; Fc1-Fc4; } \\
\text { Ed1-Ed3; E11-E14; Ec1-Ec2; T1-T3; } \\
\text { L1-L3; Lc1-Lc2; V; Vc; P1-P4; Pc }\end{array}$ \\
\hline Thoracic tergite I & M2-M4; A1- & M1-M3; A1-투; D1-D3; L1-L6; P1-P6 & M1-M3; A1- $\underline{\mathbf{A 5}} ; \mathrm{D} 1-\underline{\mathbf{D 2}} ; \mathrm{L} 1-\underline{\mathbf{L} 4} ; \mathrm{P} 1-\mathrm{P} 6$ \\
\hline Thoracic tergite II & M1-M4; A1-A6; L1-L6 $;$ P1-P6 & M1-M4; A1-A6; L1-L5; P1-P6 & 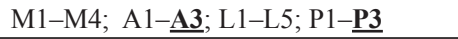 \\
\hline Thoracic tergite III & M1-M4; A1-A6; L1-L6; P1-P6 & M1-M4; A1-A6; L1-L6; P1-P6 & 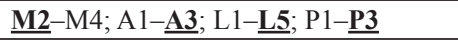 \\
\hline Abdominal tergite I & M2-M4; A1-A3; L1-L4; P1-P5 & M2-M4; A1-A3; L1-L4; P1-P5 & 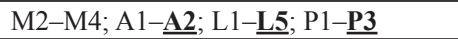 \\
\hline
\end{tabular}

L5; P1-P6. Thoracic tergite III: M1-M3; A1-A7; L1-L4; $P 1-P 6$. Abdominal tergite I: $M 1 ; A 1-A 4 ; L 1-L 3 ; P 1-P 6$. Development. From egg to pupa $\left(22-24^{\circ} \mathrm{C}\right): 12-13$ days. Behavior. Females and larvae were found in tunnels and chambers in fungal cups. An enlarged chamber was typically located at the apical end of each tunnel, where eggs covered with fungal frass were usually found. Females stayed there after oviposition before and after their eggs hatched to repel conspecific adult females and predaceous beetles of other groups. Rarely males were also present in chambers.

\section{Oxyporus (Oxyporus) major Gravenhorst, 1806}

Published data. Goodrich \& Hanley (1995): description of L3; CAMPBELL (1969): distribution.

Larval morphology. El1 located medial to uppermost stemmata; head seta $L 4$ missing; labral seta $L m 3$ missing; pronotum with $A 1-A 4$ and $P 1-P 8$ setae; mesonotum with $A 1-A 7, L 1-L 5$, and $P 1-P 6$ setae; metanotum with $A 1-A 7$, $L 1-L 4$, and $P 1-P 6$ setae; abdominal tergum I without membrane setae and $A 1-A 4$.

Development. One male and two females were collected with their host fungi, two mature larvae were found, 14 days after collection of parental adults new fully pigmented adults were found.

Behavior. Larvae were usually found in cylindrical tunnels in basidiocarps, which extended to a chamber in the central part of a cap. The presence of a single female of $O$. major in each basidiocarp that contained either eggs or larvae was interpreted by GoODRICH \& HANLEY (1995) as brood chamber guarding. Adults and larvae were available from June to October, most of which were collected in September.

\section{Oxyporus (Oxyporus) rufus Linnaeus, 1758}

Published data. Heeger (1853): description of L3; misidentified as $O$. maxillosus (GANGLBAUER 1895, KASUle 1968); notes on hosts and behavior; LIPKOW (1997): distribution.

Larval morphology. Most characters given in the species description are common for Oxyporus. Species diagnosis of last instar: head pale brown, slightly longer than wide, sclerites on body reddish-brown.

Development. Only field observations. Egg: 8-12 days; instars I-II: 8-12 days; instar III: 8-12 days; pupa: 10-14 days (see Discussion: General notes).

Behavior. According to HEEGER's (1853) field observations in Austria, adults burrow into the ground for overwintering from mid-September and reappear only in May, when they start to search for food and mating partners. Couples are reported to rarely stay together for more than 5 minutes; mating beetles change partners multiple times. In six to eight days after mating, females lay eight to 12 or 20 eggs. In cold conditions the period after mating and before oviposition may take even longer. Nevertheless, according to LIPKOw (1997), in northern Germany adults can be found from April to October, and their larvae - from the beginning of summer to October.

\section{Oxyporus (Oxyporus) stygicus Say, 1834}

Published data. Hanley \& Goodrich (1994): description of E, L3, P, biology and hosts; CAMPBELL (1969): distribution.

Larval morphology. Characters of larva to distinguish it from that of $O$. vittatus: Ell located anterior to, and medially from, to uppermost ocelli; head seta $L 4$ present; $3 A$ and $3 P$ setae on pronotum; $5 A$ and $6 P$ setae on mesonotum; $6 A$ and $7 P$ setae on metanotum; $4 A$ setae on abdominal tergum I. Body setae median length is bigger than of $O$. vittatus.

Development. From egg to imago $\left(22-24^{\circ} \mathrm{C}\right)$ : $16-18$ days; egg: 1-2 days; instar I: 1-2 days; instar II: 1-2 days; instar III: 1-2 days; pupa: 7-10 days. Moults were not observed. Instead, three groups of collected and preserved larvae with different body length were interpreted as three larval instars, respectively.

Behavior. Adults were most commonly collected from fully mature Pleurotus ostreatus mushrooms in association with other Oxyporus or Triplax Herbst, 1793 (Coleoptera: Erotylidae) species.

\section{Oxyporus (Oxyporus) vittatus Gravenhorst, 1802}

Published data. Leschen \& Allen (1988): description of E, L3, P, biology and hosts; HANLEY \& GOODRICH (1994): notes on L3 morphology, fungal hosts; CAMPBELL (1969): distribution.

Larval morphology. Head and body sclerites without pigmentation, long non-articulated spines on mala, prementum with lateral setae 1/2 length of medial setae (LESCHEN \& 
AlLEN 1988). The earlier claimed absence of sublateral setae was rejected by observations in HANLEY \& GOODRICH (1994). Characters to distinguish this species from $O$. stygicus are as follows: Ell located medial to uppermost ocelli; head seta $L 4$ absent; $4 A$ and $4 P$ setae on pronotum; $7 A$ and $5 P$ setae on mesonotum; $4 A$ and $4 P$ setae on metanotum; no anterior setae on abdominal tergum I. Development. Egg: 6 hours; instar I: 16.5 hours; instar II: 1.17 days; instar III: 5.86 days; prepupae: 3.6 days; pupae: 5.75 days. Total development duration: 17 days.

Behavior. Adults have been collected from April to October with the highest abundance during September and October. Preoral digestion of larvae was observed (LESCHEN \& AlLEN 1988)

\section{Subgenus Pseudoxyporus Nakane \& Sawada, 1956}

\section{Oxyporus (Pseudoxyporus) lateralis Gravenhorst, 1802}

Published data. McCabe \& Teale (1981): L3 morphology; Campbell (1969): distribution.

Larval morphology. Genus descriptions characters, no data on chaetotaxy of third instar larva. MCCABE \& TEALE (1981) wrongly suggested that larvae of this species have four-segmented antennae, presumably because they miscounted the elevated area at the antennal socket as the first antennal segment.

Development. Duration of life stages unknown.

Behavior. Larval tunnels in fungal cups and stalks were observed. Larvae move in a quick, jerky fashion (McCABE \& Teale 1981). The species is active from April to November, but most of the specimens (adults and larvae) were collected in September and October.

\section{Oxyporus (Pseudoxyporus) occipitalis Fauvel, 1864}

Published data. LeSCHEN \& AlLen (1988): morphological description of E, L3 without chaetotaxy, P; HANLEY \& Goodrich (1993): hosts and distribution.

Larval morphology. Head and body sclerites without pigmentation; prementum with lateral setae $1 / 4$ times as long as medial setae, sublateral setae absent; from two to three articulated spines on the inner lobe of mala.

Development. According to Leschen \& AlLEN (1988), the third instar larvae left the fungal fruit body four days after collection and afterwards developed into adults in five days. HANLEY \& GOODRICH (1993) showed that full development in laboratory at room temperature from egg to imago is very short and takes only 17 days as follows: egg: several hours; instar I: approximately one day; instar II: appr. one day; instar III: appr. six days; pupa: appr. six days.

Behavior. Females were typically laying eggs in the chamber built inside the gill layer of the fungi (LESCHEN \& Allen 1988). According to HANLEy \& GoOdRICH (1993), $O$. occipitalis were collected only from the mature fungal fruit bodies. A male and female were once seen copulating on a host fungal cap. Hatching was said to begin several hours after collecting the eggs. In the Pacific Northwest (USA) this species was collected mostly in October, but overall across its range from September to November.

\section{Biology of Oxyporus: the previous knowledge and the new data}

Feeding. Since the first report of the mycophagy for $O x y$ porus by HeEger (1853), it was repeatedly mentioned for this genus ever since. But only a century later, SCHEERPELTZ \& HöFLER (1948) reported that Oxyporus feed on fungi both as adults and larvae, which was important because larval fungal diet is an essential condition for obligate mycophagy (KompantSeVa \& Schigel 2000). CAmpBell (1969), however, suggested that Oxyporinae should be partially predaceous because of their mandibles, which are long with a cutting edge in adults and bifurcate with serrate margin in larvae. Newton (1984) emphasized that these beetles feed solely on fungal fruit bodies during their entire life cycle. LESCHEN \& Allen (1988) described the actual feeding mechanism for both adults and larvae and confirmed NewTon's (1984) assumption about preoral digestion in Oxyporinae. In particular, they observed $O$. vittatus larvae keeping 'a ball of fluid in their food meatus which they could bring into their mouths'. HANLEY \& GoOdRICH (1995) revealed more morphological adaptations of mycophagy in adults, such as labrum which forms a container for preoral digestion when mandibles are open, denticles on the anterior surface and brush-like structure on the posterior region of the mandibles which broaden the surface area of a fungal slice for exposure of digestive enzymes, and the notch-like structure on the left mandible which protects the cutting edge of mandibles from damage and correctly aligns them when quiescent. They also noted a remarkable behavior in larvae, which use mandibles not only for slicing fungal tissue, but also for placing their remnant chunks between fungal gills in the burrows they make, probably to camouflage their presence in the fungus.

Our observations of the feeding larvae of $O$. maxillosus, $O$. procerus, and $O .(P)$. melanocephalus recorded the same habits. Each larva grabbed a chunk of a mushroom by the mandibles, then twisted it with the help of the maxillae and labium and macerated it with digestive liquid from the epipharyngeal duct. Processed that way, a fungal chunk was soon condensed ca. two times in its volume to become a brown 'brick' in the 'wall' that the larva was building across the tunnel by means of the forward rotating movement of its maxillae and labium to repair damaged parts of galleries.

Mating behavior. Along with the feeding, Oxyporus use fungal fruit bodies as an aggregation place for meeting a mating partner, hiding from predators, and building nesting chambers for oviposition. Our repeated field observations in August and September 2018 in Primorsky region revealed tens of conspecific Oxyporus adults in a single big cap of fungi such as Laetiporus sulphureus, Russula aeruginea Lindblad ex Fr. 1863, or in a cluster of caps of Pholiota sp. Often such aggregations included individuals of more than one species with a relatively equal number of males and females for each species. Since no egg chambers were ever seen in big caps (mostly of Laetiporus sulphureus) with such a notable specimen and species assemblages, we conclude that such fungi serve only as a microhabitat for adult Oxyporus where they feed and mate before dispersing to other fungal caps used for breeding. 
Table 4. Fungal hosts currently known for Oxyporus adults and larvae. Data derived from publications specifically dealing with natural history of the group. Occasional records for adult specimens not included.

\begin{tabular}{|c|c|c|}
\hline Species & Fungal hosts for larvae & Fungal hosts for adults \\
\hline \multicolumn{3}{|l|}{ Subgenus Oxyporus s.str. } \\
\hline $\begin{array}{l}\text { Oxyporus (s.str.) femoralis } \\
\text { Gravenhorst, } 1802\end{array}$ & $\begin{array}{l}\text { Strophariaceae: Hypholoma fasciculare } \\
\text { (Huds.) P. Kumm. (LESCHEN \& AlLEN 1988) }\end{array}$ & $\begin{array}{l}\text { Amanitaceae: Amanita sp., Amanita rubescens Pers. Marasmia- } \\
\text { ceae: Marasmius sp. Physalacriaceae: Armillaria mellea (Vahl) } \\
\text { P. Kumm, Desarmillaria tabescens (Scop.) Singer. Pleurotaceae: } \\
\text { Pleurotus sp. Pluteaceae: Pluteus cervinus (Schaeff.) P. Kumm. } \\
\text { Russulaceae: Lactarius sp. Strophariaceae: Hypholoma fascicu- } \\
\text { lare (Huds.) P. Kumm., Hypholoma lateritium (Schaeff.) P. Kumm. }\end{array}$ \\
\hline
\end{tabular}

\begin{tabular}{ll}
\hline Oxyporus (s.str.) germanus & Suillaceae: Suillus sp. (HwANG \& AHN \\
Sharp, 1889 & 2002)
\end{tabular}

Oxyporus (s.str.) japonicus

Sharp, 1889
Omphalotaceae: Omphalotus guepini-

formis (Berk.) Neda. (Hanley \& SETSuda 1999) (Leschen \& Allen 1988, CAmpBell 1969)

Agaricaceae: Agaricus sp. Boletaceae: Heimioporus japonicus (Hongo) E. Horak, Xerocomus sp. Marasmiaceae: Marasmius sp. Suillaceae: Suillus spp. (HwAng \& Aнn 2002).

Omphalotaceae: Omphalotus guepiniformis (Berk.) Neda. Physalacriaceae: Armillaria mellea (Vahl) P. Kumm. Pleurotaceae: Hohenbuehelia serotina (Pers.) Singer, Pleurotus ostreatus (Jacq.) P. Kumm. Strophariaceae: Pholiota lenta (Pers.) Singer. (Hanley \& SETSUda 1999)

\begin{tabular}{ll}
\hline Oxyporus (s.str.) major & Strophariaceae: Stropharia hardii G.F. \\
Gravenhorst, 1806 & Atk. (HANLEY \& GOODRICH 1995)
\end{tabular}

Boletaceae: Boletus sp. Physalacriaceae: Armillaria gallica Marxm. \& Romagn., Armillaria mellea (Vahl) P. Kumm., Desarmillaria tabescens (Scop.) R.A. Koch \& Aime. Russulaceae: Lactarius sp., Russula sp. Strophariaceae: Pholiota sp. (HANLey \& GoODRICH 1995)

Oxyporus (s.str.) maxillosus Fabricius, 1793

Cortinariaceae: Cortinarius sp. Physalacriaceae: Armillaria sp. Strophariaceae: Pholiota sp. Suillaceae: Suillus americanus (Peck) Snell

Boletaceae: Leccinum holopus (Rostk.) Watling. Cortinariaceae: Cortinarius sp. Physalacriaceae: Armillaria sp. Fomitopsidaceae: Laetiporus sp. Strophariaceae: Kuechneromyces sp., Pholiota aurivella (Batsch) P. Kumm., Pholiota sp. Pleurotaceae: Pleurotus ostreatus (Jacq.) P. Kumm., Pleurotus pulmonarius (Fr.) Quél. Suillaceae: Suillus americanus (Peck) Snell, Suillus sp. (this paper); Strophariaceae: Pholiota lucifera (Lasch) Quél. (ScheERPELTZ \& HöFLER 1948)

\begin{tabular}{ll}
\hline $\begin{array}{l}\text { Oxyporus (s.str.) procerus } \\
\text { Kraatz, } 1879\end{array}$ & Pleurotaceae: Pleurotus sp. (this paper) \\
\hline Oxyporus (s.str.) rufus & Agaricaceae: Agaricus pratensis Schaeff., \\
Linnaeus, 1758 & A. edulis Vill. (HeEGER 1853)
\end{tabular}

Pleurotaceae: Pleurotus sp. Fomitopsidaceae: Laetiporus sulphureus (Bull.) Murrill (this paper) (HeEger 1853). Boletaceae: Caloboletus radicans (Pers.) Vizzini. Fistulinaceae: Fistulina hepatica (Schaeff.) With. Physalacriaceae: Xerula pudens (Pers.) Singer (SCHEerpeltz \& HöFler 1948)

Oxyporus (s.str.) stygicus Say, 1834
Omphalotaceae: Omphalotus illudens (Schwein.) Bresinsky \& Besl. Strophariaceae: Pholiota aurivella (Batsch) P. Kumm (HANLEY \& GOODRICH 1994) Strophariaceae: Pholiota aurivella (Batsch) P. Kumm., Pholiota sp. Grifolaceae: Grifola frondosa (Dicks.) Gray. Polyporaceae: Polyporus squamosus (Huds.) Fr. Physalacriaceae: Armillaria gallica Marxm. \& Romagn. Omphalotaceae: Omphalotus illudens (Schwein.) Bresinsky \& Besl. Pleurotaceae: Pleurotus ostreatus (Jacq.) P. Kumm (HANLEY \& GoOdRich 1994)

Oxyporus (s.str.) vittatus Gravenhorst, 1802 Cortinariaceae: Cortinarius sp. (LESCHEN \& AlLen 1988)

Amanitaceae: Amanita sp. Boletaceae: Boletus sp., Leccinum sp. Cortinariaceae: Cortinarius sp. Hydnangiaceaea: Laccaria amethystina Cooke. Hymenogastraceae: Naucoria sp. Marasmiaceae: Marasmius sp., Megacollybia platyphylla (Pers.) Kotl. \& Pouzar. Physalacriaceae: Armillaria mellea (Vahl) P. Kumm. Strophariaceae: Hypholoma perplexum (Peck) Sacc. Pleurotaceae: Pleurotus ostreatus (Jacq.) P. Kumm. Suillaceae: Suillus sp. (LESCHEN \& Allen 1988, HANLey \& GoOdrich 1994).
Subgenus Pseudoxyporus Oxyporus (P.) lateralis Gravenhorst, 1802
Physalacriaceae: Armillaria mellea (Vahl) P. Kumm. Pleurotaceae: Pleurotus ostreatus (Jacq.) P. Kumm. Strophariaceae: Pholiota sp. (Paulian 1941, McCABE \& Teale 1981).

Oxyporus (P.) melanocephalus Strophariaceae: Pholiota sp. (this paper) Kirschenblatt, 1938

Oxyporus (P.) occipitalis Fauvel, 1864 Hygrophoraceae: Hygrophorus russula
(Schaeff. ex Fr.) Kauffman. (LESCHEN \& AlLen 1988). 

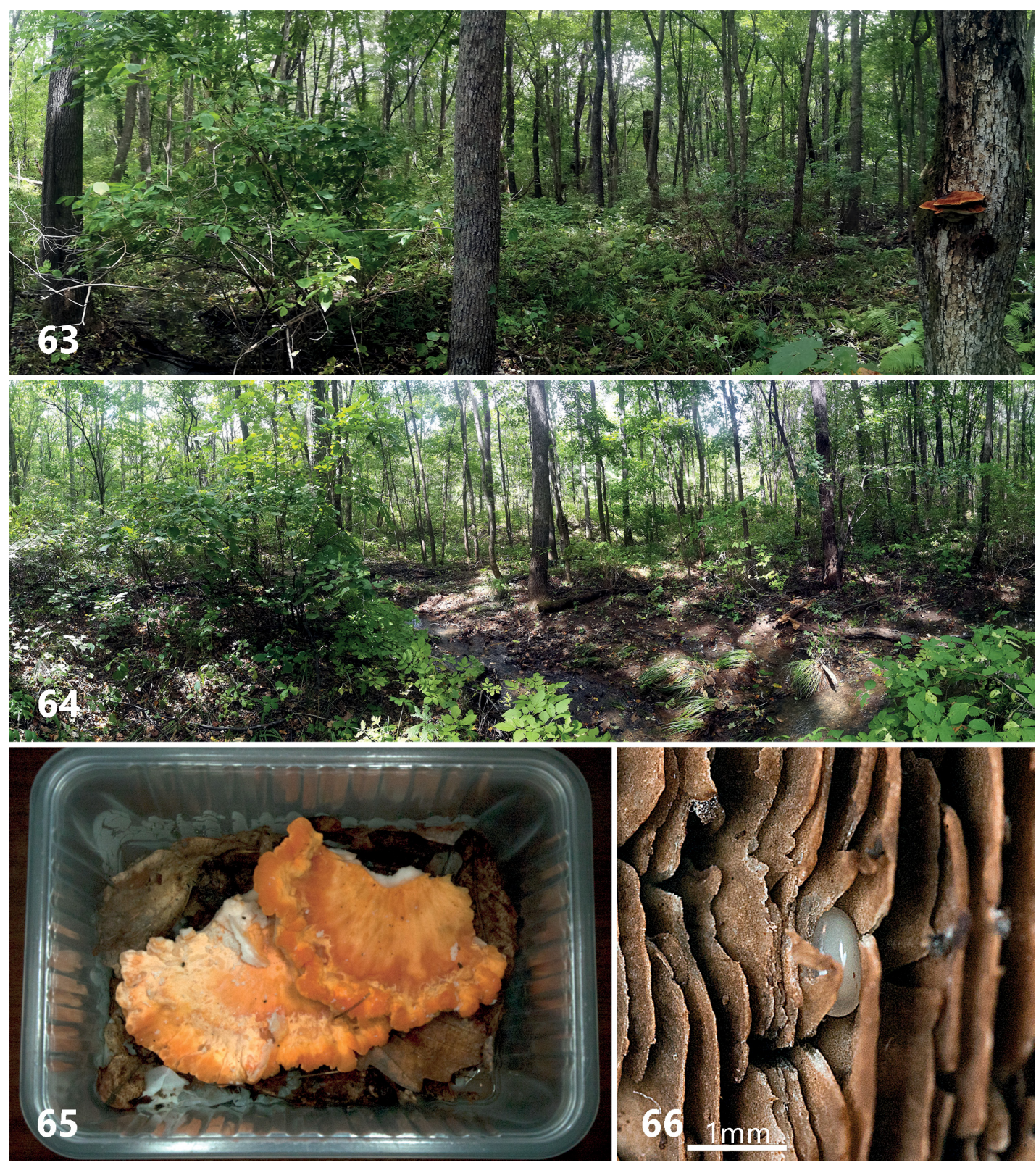

Figs 63-66. Habitat and rearing of Far East Oxyporus species. 63 - aspen-maple forest with lime-trees in a lowland of the Arboretum of the Gornotaezhnaya Station, locality of Oxyporus (P.) melanocephalus. 64 - oak forest on a hill of the Arboretum of the Gornotaezhnaya Station, locality of Oxyporus maxillosus. 65 - rearing box with the sand layer, the leaf litter and a fruit body of Laetiporus sulphureus. 66 - an egg of Oxyporus (Pseudoxyporus) melanocephalus Kirschenblatt, 1938 nested between the gills of Pholiota sp.

Brood care and tunneling behavior. After mating, which may take place in a different fungal cap, females prepare a place inside a fungal fruit body for oviposition. SETSUDA (1994) conducted an experiment to provide evidence for the brood care of $O$. japonicus and to explore its chamber construction behavior. According to his research, females of $O$. japonicus construct one to three chambers inside a fungal cap, lay egg clusters inside each chamber and cover them with fungal frass. Each female remains with the laid eggs, protecting them from predators until hatching. Protection is also needed from conspecific females because they can destroy eggs, probably in order to occupy the already constructed chamber and lay their own eggs there (SETSUDA 1994). Female behavior of piling up fungal frass as a plug closing the openings of such chambers has been repeatedly observed for the European (SCHEERPELTZ \& HöFLER 1948, LipKow 1997), American (Leschen \& Allen 1988, Navar-
rete-Hereida \& Novelo-Guttierrez 1990), and Oriental (Setsuda 1994) Oxyporus species. Our field observations of the females of $O$. maxillosus, $O$. aequicollis, $O$. basicornis, and $O$. niger support the earlier published data which were mentioned above on the details of chamber construction. We can add that the number of chambers in one cap, or eggs in each cluster, as well as configuration of tunnels may vary within one species. Actually, the behavior seems different in $O$. (P.) melanocephalus, in which we observed a female laying eggs one by one between different gills of a fungal cap. Their first instar larvae hatched one by one from eggs hidden deeply between gills and began feeding by tunneling the cap at the base of gills, staying away from the hymenophore surface. Because of such distributed larval impact, the fungal fruit body looked intact.

Life stages duration. The life cycle of Oxyporus consists of six stages: an egg, three larval instars, pupa, and imago 
(CAmpbell 1969, McCabe \& Teale 1981, Leschen \& Allen 1988, HANLey \& GoOdRICH 1994, GoOdRICH \& HANLEy 1995, Hanley \& Setsuda 1999, Hwang et al. 2002). The duration of each immature stage and the whole development from egg to imago takes a couple of weeks, for example 16-18 days for $O$. stygicus and 22 days for $O$. (P.) melanocephalus. In Oxyporus it is shorter in comparison to diverse Staphylinidae living in the ground-based debris (e.g. up to one month in Steninae (WeINREICH 1968); 1.5-2 months in laboratory for various Staphylininae (Pietrykowska-Tudruj \& StaineC 2012; PietrykowsKa-Tudruj et al. 2014); several months including overwintering larvae for temperate Omaliinae (THAYER 1985)), but similar to staphylinids developing in dung (LipKow 2011). Larvae of Oxyporus feed, starting seconds after hatching (LESCHEN \& ALLEN 1988, HANLEy \& SETSUdA 1999). After the second moult they turn pink, and then stop feeding in some days and fall from the rapidly degrading fungal cap on the ground where they dig into the soil to pupate. For pupation larvae build a small pupal chamber, fortifying the soil around and only then become motionless prepupa (LesChEN \& ALLEN 1988, HANLEY \& GOODRICH 1994, Goodrich \& Hanley 1995, Hanley \& Setsuda 1999, our field observations). Presumably, new imagoes remain in pupal chambers until becoming fully sclerotized, or longer during dry periods in summer, or probably even during the winter until the next mating season. Unfortunately, we did not find any clear published data on the overwintering stage in Oxyporus.

\section{Discussion}

The interest in Oxyporus biology and immature stages has notably increased at the end of the past century when the growing knowledge of morphology and chaetotaxy of Oxyporinae larvae significantly facilitated understanding of their characters. For example, sensorial structures on the apex of last palpomere of $O$. stygicus, O. major, O. occipitalis, O. japonicus, and O. germanus (LESCHEN \& ALLEN 1988; Hanley \& Goodrich 1994, 1995; Hanley \& Setsuda 1999; Hwang et al. 2002) were finally revealed. Certain descriptions were updated with the new set of characters, like the second instar of $O$. japonicus described by HANLEY \& SETSUDA (1999). However, new data brought new problems, for example poor comparability of the growing number of larval descriptions. Among the eight most recent descriptions of the Oxyporus larvae (McCabe \& Teale 1981, Leschen \& Allen 1988, Hanley \& GoOdRich 1994, GoOdRich \& Hanley 1995 , Hanley \& Setsuda 1999, Hwang et al. 2002), chaetotaxy was examined in detail only in four of them (O. stygicus by HaNley \& GoOdrich 1994, O. major by GoOdRich \& Hanley 1995, O. japonicus by Hanley \& Setsuda 1999, O. germanus by HwANG et al. 2002). Difficulty in applying the Aleocharinae-based chaetotaxy system to Oxyporinae was one of the factors that led to numerous discrepancies in homology assessments mentioned further in the Remarks on chaetotaxy section. Some of these and other inaccuracies and mismatches in the descriptions should be mentioned to avoid new mistakes in the future research.

Species-specific characters. All described larvae of $O x y$ porus appear morphologically very uniform including their chaetotaxy. Only a small set of chaetotaxy characters is usu- ally species-specific. Oxyporus (P.) melanocephalus has the most pronounced set of unique characters compared to $O$. (s. str.) maxillosus, $O$. (s. str.) procerus and other species from the nominative subgenus. Oxyporus $(P$.$) melanocephalus$ has two lateral c. s. $(L c 1-L c 2)$ and one ventral campaniform sensillum $(V c)$ on each side of the head capsule compared with one lateral and no ventral c. s. in $O$. (s. str.) maxillosus and $O$. (s. str.) procerus; smaller number of posterior setae on metanotum and abdominal tergites in the former, compared to more of them in other species with data available; location of dorsal c. s. on mala between two lateral setae above medial seta and under palpifer in the former (not above the proximal lateral setae as in $O$. (s. str.) maxillosus and $O$. (s. str.) procerus); and reduced but still distinct ligula, which is absent in other species. Presumably, these characters may be candidates for subgenus specific characters but need to be tested when more data on larvae of Pseudoxyporus become available.

Remarks on chaetotaxy. The indexation of setae on labrum and adjacent area of frons seems controversial when comparing larval morphology descriptions of various Oxyporus species among each other, or with Atheta coriaria in ASHE $\&$ Watrous (1984). Based on the description of O. major in GOODRICH \& HANLEY (1995), we assumed that the Ll2 seta does not belong to nasale which is delimited by the position of labro-frontal suture. So it would be more accurate to name it Fll. Goodrich \& Hanley (1995) decided that the Em (epicranial medial) row was missing in $O$. stygicus and $O$. major, and it is not clear why not the $E l$ (epicranial lateral) row is missing from their point of view. However, even though we do not see strong evidence for this homology, we accept their hypothesis of the missing Em for practical reasons, to make our descriptions compatible. For the same reasons we accept the renaming of the Ec3 of Atheta coriaria to $P c$ for the Oxyporus, even though true homology remains unclear here too. Probably the most essential difference between the Atheta and Oxyporus chaetotaxy is that anterior rows of tergal setae $(A)$ in Atheta are believed to be present on the tergal plate on pronotum and on the membranes anterior to meso- and metanotal tergal plates, while in Oxyporus the anterior row is constantly located at the anterior margin on the tergal plate and microsetae on membrane have their own name $(M)$.

The patterns of tergal setae (anterior, discoidal, lateral and posterior rows: $A 1-A 6, D 1-D 3, L 1-L 6$ and $P 1-P 6)$ may look ambiguous in our figures for $O$. maxillosus because of the distorted distances between the pictured setae. However, we stress that they are easily observed on other tergites and in other species of Oxyporus.

There is a case of the incongruent homology between some setae in the descriptions of $O$. germanus and O.japonicus. Oxyporus germanus was said to have four $F l$ while $O$. japonicus had three $F l$, but only because $L l 2$ in $O$. japonicus was recognized as Fll in $O$. germanus, and Fll in $O$. japonicus as $F l 2$ in O. germanus. As we assume from Figs 2 and 6 in Hanley \& Setsuda (1999), and from Figs 2 and 7 in HwANG et al. (2002), there is no difference in the number of $\mathrm{Ll}$ and $\mathrm{Fl}$ setae between $O$. germanus and $O$. japonicus. The same problem applies to $V l 1$ and $V l 2$ setae, which are called $L 1$ and $L 3$ respectively in other descriptions. The 
seta which is called $\mathrm{Vl}$ in the description of $O$. germanus by HWANG et al. (2002) is here named $L 3$ because we consider it more likely homologous with such of Atheta coriaria than with $V l$, according to its topology. Microsetae anterior to the pronotum are named as their supposed analogs anterior to the mesonotum and metanotum. Moreover, in our description campaniform sensilla are taken into account and their presence and topology is revised more carefully, using SEM, which also helped to distinguish between the campaniform sensilla and the pore-like structures $(p l s)$.

A character that is not mentioned in descriptions of Atheta and Oxyporus is a group of membrane microsetae between the head and pronotum. There is no name for such setae even if they are shown in figures. For simplicity we name them the same as all other thoracic membrane microseta for Oxyporus (M1-M4). However, we do not have any evidence of their homology.

The antennal apical complex, here explored with SEM as well, turned out to be a group of sensilla consisting of one thickened membranous solenidium, two narrow spiny solenidia, and one microseta (Fig. 41). This is different from 'three apical setae and three apical microsetae', as it was interpreted before (HANLEY \& GoOdRICH 1995, HwANG \& AHN 2002).

The leg of O. japonicus in Hanley \& SETSUdA (1999) was pictured with setae of anterior and posterior projections misleadingly combined in one layer where some setae, in addition, were missed. That led to mistakes in comparison of O. japonicus and O. germanus in HwANG et al. (2002). In particular, it was stated that $O$. germanus has eight setae on femur and nine on tibia compared with $O$. japonicus which has seven and eight, respectively. However, this mismatch could be caused by setae on the distal side of the femur and tibia of $O$. japonicus which were occasionally not taken into account. An analogous mistake appears in the description of O. (P.) lateralis (McCABE \& TEAlE 1981), where the ventral view of maxilla in Fig. 7 included setae from other projections. The presence of three $P$ microsetae instead of four in O.japonicus is probably a misinterpretation. Along with that, the difference between these two species in the number of posterior rows of setae on the abdominal tergum I may be based on one unaccounted pair of lateral seta of $O$. japonicus. Finally, the only type of sensilla earlier accounted in the papers on Oxyporus larvae were simple trichoid sensilla and sensory appendages of antennae, whereas multiple campaniform sensilla were not classified or even pictured in some of them.

General notes. Regarding biological and behavior observations, there is one which we find worthy of attention, even though it was a single record. The female of $O$. (P.) melanocephalus was seen laying each egg separately deep between fungal gills and not building chambers for oviposition as many Oxyporus s. str. species do (NEwTON 1984, Leschen \& Allen 1988, Setsuda et al. 1992). This seems to be a hiding brood strategy rather than a brood care. In Oxyporus s. str. with brood care, the eggs are laid in clusters and larvae initially stay together. Larvae of $O$. $(P$.) melanocephalus were observed hatching separately one by one, they also started feeding and boring tunnels separately, giving no signs on the fungal surface of their presence insi- de the fungus. In this respect it is noteworthy that HANLEY $\&$ GoODRICH (1993) reported chamber construction for $O$. (P.) occipitalis. We guess that it could be phylogenetically informative to study the reproductive behavior of a bigger sample of species across both subgenera. There is also a striking difference between two subgenera in our pairwise nucleotide distance analysis, which has shown a distance of $0.17-0.18$ and of 0.19 between $O$. (P.) melanocephalus and $O$. (s. str.) procerus, and $O$. (P.) melanocephalus and $O$. (s. str.) maxillosus, respectively. At the same time, such distance between $O$. (s. str.) procerus and $O$. (s. str.) maxillosus was valued as 0.07 . So far, given all observed morphological (also stressed in MAKRANCZY 2012), molecular and presumed biological distance between Oxyporus s. str. and Pseudoxyporus, the return to their original status as separate genera may seem justified.

One more noticeable mismatch between our data and the experience of previous authors concerns the life cycle duration of $O$. rufus. HeEger (1853) reported this to be 34-50 days from eggs to adults, instead of 16-22 days known for all other Oxyporus species. We believe that HEEGER's (1853) notes may contain some mistake; probably one stage duration was counted twice. His description includes no data on the conditions of his observations, but it is mentioned that they were taken in the field. There is no information on whether any larvae were reared and which temperature was applied for that. Thus, O. rufus larval morphology and biology still needs to be explored.

HANLEY \& GOODRICH (1994), who revealed patterns of fungal host specificity for Oxyporinae of the New World, have suggested five patterns, based on observations of large numbers of host records. Pattern 1 includes species with widely broad overall host selection and broad subset of preference, pattern 2 - species with broad overall host selection but narrow set of preference, pattern 3 - species with narrow overall host selection and narrow set of preference, pattern 4 - species with narrow overall host selection without any defined set of preference, pattern 5 - species with adults specific to one species of fungi. According to HANLEY \& Goodrich (1995), O. japonicus belongs to the third pattern of host selection. HwANG \& AHN (2002) assumed that $O$. germanus fits the third pattern, the same as $O$. japonicus. They based that on the observation that adults were collected from five genera of four families of fungi, showing a preference ( $90 \%$ of all collected specimens) to one genus (Suillus sp.). We believe that such classification of host selection can be useful, but needs a bigger number of better comparable host records.

It is well known that on a broader scale larval characters have played a significant role in the exploration of a higher classification of Coleoptera since CROwSON (1960). Such significance of larval characters was also recognized for Staphylinidae by РототSкAYA (1967), Tichomirova (1970) and others, but the immature stages are still not implemented full scale for phylogenetic and systematic research across this big family. Our updated description of the third instar larva of Oxyporus suggests that, based on medium sclerotization of a head capsule, absence of the cervical constriction, stemmata arranged in rows, distinct sutures, presence of the labrum, etc., Oxyporus belongs to the so- 
-called aleocharomorphic group of rove beetle subfamilies according to РототsкауA (1967). The phylogenetic value of her division of rove beetle larvae into the aleocharomophic and staphylinomorphic types has never been tested, but is worthy of further investigation.

Summing up, our study has answered some questions but also raised new ones. Further exploration of the origin and functions of the $p l s$, as well as establishing homology between various sensilla of Oxyporus and Atheta coriaria would lead to a better understanding of the evolution of these elements across Staphylinidae and increase their value as characters for phylogenetic reconstructions. A uniform chaetotaxy system for Staphylinidae comparable with systems used in other beetle families such as Carabidae (MAKARov 2002, 2008), Hydrophilidae (FIKÁČEK et al. 2008) or Hydraenidae (Delgado et al. 2005) could shed light on the sister group relationships of Oxyporinae and similarly controversial lineages within the family. Also, it could integrate larval characters of staphylinids into the framework of the entire beetle order. Probably, this system should be based on the first instar larvae, which, according to the studies on Carabidae (BousqueT \& Goulet 1984), possess more characters significant for the phylogeny. More than that, first instar larvae give the researcher access to only primary chaetotaxy, which is easier to homologize across the family (BOUSQUET \& Goulet 1984). Unfortunately, as we see in Oxyporus, the first instar larvae are much less known than mature instars. Regarding biological observations, quantitative data on the host fungi for larvae of different Oxyporus species can help to answer the question of whether widespread species are less host-specific than those with restricted distribution. Observations on mating, oviposition, larval feeding and other aspects of natural history broadly across the genus would help to understand its evolution. Finally, a proper taxonomic revision of Oxyporinae is needed to facilitate all these explorations.

\section{Acknowledgements}

We sincerely acknowledge S. A. Shabalin (Federal Scientific Center of the East Asia Terrestrial Biodiversity, Far Eastern Branch of the Russian Academy of Sciences (FEB RAS), Vladivostok) for providing us a part of his baseline data and for essential field notes on common habitats and biology of the Far Eastern Oxyporus. We also thank A. V. Kuprin and M. M. and N.V. Omelko for the accommodation and support at the Gornotaezhnaya Station FEB RAS. We are very thankful to K.V. Makarov (Moscow State Pedagogical University, Moscow) for the provided material, essential advice and tutorial on the chaetotaxy. Special thanks go to L. B. Kalinina (Komarov Botanical Institute RAS, Saint Petersburg) for the identification of host fungal species. We are grateful to Anna A. Namyatova (All-Russian Institute of Plant Protection RAS, Saint Petersburg) for the tutorial and support on the molecular part of the research and Alexey Mirolyubov for assistance with SEM. Comments by the editor (Martin Fikáček) and two reviewers (Ewa Pietrykowska-Tudruj, José Luis Navarrete Heredia) have contributed significantly to this article. Our English colleague Josh Jenkins Shaw (Institute of Zoology of the Chinese Academy of Science, Beijing) kindly read our paper and improved the language. We acknowledge resource centers "Chromas", "Molecular and Cell Technologies", and "Centre for Microscopy and Microanalysis" (Saint Petersburg State University) for access to the laboratory equipment and technical assistance. We thank our colleagues from the Zoological Institute for the access to the Staphylinidae collection of the Zoological Institute, Russian Academy of Sciences, which is financially supported by the state research project AAAA-A19-119020690101-6. Funding for this study was partly provided by two Saint Petersburg State University research grants (Pure SPBU ID 43189948 and 39446308), and Ernst Mayr Travel Grant 2019.

\section{Bibliography}

ASHE J. S. \& WATROUS L. E. 1984: Larval chaetotaxy of Aleocharinae (Staphylinidae) based on a description of Atheta coriaria Kraatz. Coleopterists' Bulletin 38(2): 165-179.

BOUSQUET Y. \& GOULET H. 1984: Notation of primary setae and pores on larvae of Carabidae (Coleoptera: Adephaga). Canadian Journal of Zoology 62(4): 573-588.

CAI C. \& HUANG D. 2014: Diverse oxyporine rove beetles from the Early Cretaceous of China (Coleoptera: Staphylinidae). Systematic Entomology 39: 500-505.

CAI C., LESCHEN R. A., HIBBETT D. S., XIA F. \& HUANG D. 2017: Mycophagous rove beetles highlight diverse mushrooms in the Cretaceous. Nature Communications 8(14894): 1-7.

CAMPBELL J. M. 1969: A revision of the new world Oxyporinae (Coleoptera: Staphylinidae). Canadian Entomologist 101(3): 225-268.

CROWSON R. A. 1960: The phylogeny of Coleoptera. Annual Review of Entomology 5(1): 111-134.

DELGADO J.A. \& ARCHANGELSKY M. 2005: Description of the larval stages of Gymnochthebius jensenhaarupi and phylogenetic analysis of the relationships with other species of the subfamily Ochthebiinae (Coleoptera: Hydraenidae). European Journal of Entomology. 102(2): 231-240.

ERICHSON G. F. 1839: Genera et species Staphylinorum. Humboldt-Universität zu Berlin, Berlin. 954 pp.

FAUVEL C. A. A. 1872: Faune Gallo-Rhénane ou species des insectes qui habitent la France, la Belgique, la Hollande, le Luxembourg, la Prusse rhénane, le Nassau et le Valais avec tableaux synoptiques et planches gravées. F. Le Blanc-Hardel, 464 pp.

FIKÁČEK M., ARCHANGELSKY M. \& TORRES P. 2008: Primary chaetotaxy of the larval head capsule and head appendages of the Hydrophilidae (Coleoptera) based on larva of Hydrobius fuscipes (Linnaeus, 1758). Zootaxa 1874(1): 16-34.

FOLMER O., HOEH W. R., BLACK M. B. \& VRIJENHOEK R. C. 1994: Conserved primers for PCR amplification of mitochondrial DNA from different invertebrate phyla. Molecular Marine Biology and Biotechnology 3: 294-299.

FRANTSEVITCH L., GORB S., RADCHENKO V., GLADUN D., POLILOV A., CHERNEY L., BROWDY V. \& KOVALEV M. 2015: Lehr's fields of campaniform sensilla in beetles (Coleoptera): Functional morphology. II. Wing reduction and the sensory field. Arthropod Structure and Development 44(1): 1-9.

GANGLBAUER L. 1895: Die Käfer von Mitteleuropa. Die Käfer der osterreichisch-ungarischen Monarchie, Deuschlands, der Schweiz, sowie des französischen und italienischen Alpengebietes. 3. Bd., 1. Hälfte: Familienreihe Staphylinoidea. Theil I. Staphylinidae, Pselaphidae. Carl Gerold's Sohn, Wien, 880 pp.

GOODRICH M. A. \& HANLEY R. S. 1995: Biology, development and larval characters of Oxyporus major (Coleoptera, Staphylinidae). Entomological News 106(4): 161-168.

GREBENNIKOV V. V. \& NEWTONA. F. 2009: Good-bye Scydmaenidae, or why the ant-like stone beetles should become megadiverse Staphylinidae sensu latissimo (Coleoptera). European Journal of Entomology 106(2): 275-301.

HANLEY R. S. \& GOODRICH M. A. 1993: Biology, life history and fungal hosts of Oxyporus occipitalis (Coleoptera: Staphylinidae), including a descriptive overview of the genus. Proceedings of the Washington State Entomological Society 55: 1003-1007.

HANLEY R. S. \& GOODRICH M. A. 1994: Natural history, development and immature stages of Oxyporus stygicus Say (Coleoptera: Staphylinidae: Oxyporinae). Coleopterists' Bulletin 48(3): 213-225. 
HANLEY R. S. \& GOODRICH M. A. 1995: Review of mycophagy, host relationships and behavior in the New World Oxyporinae (Coleoptera: Staphylinidae). Coleopterists' Bulletin 49(3): 267-280.

HANLEY R. S. \& SETSUDA K. 1999: Immature stages of Oxyporus japonicus Sharp (Coleoptera: Staphylinidae: Oxyporinae), with notes on patterns of host use. Pan-Pacific Entomologist 75(2): 94-102.

HANSEN M. 1997: Phylogeny and classification of the staphyliniform beetle families (Coleoptera). Biologiske Skrifter 48: 1-339.

HEEGER E. 1853: Beiträge zur Naturgeschichte der Insecten. Sitzungsberichte der Kaiserlichen Akademie der Wissenschaften in Wien 10: 1-3, Plate 1.

HERMAN L. 2001: Staphylinidae: Oxyporinae. Pp. 1971-1994. In: Catalog of the Staphylinidae (Insecta: Coleoptera). 1758 to the end of the second millennium. IV. Staphylinine Group (Part 1). Bulletin of the American Museum of Natural History, 2440 pp.

HUNT T., BERGSTEN J., LEVKANICOVA Z., PAPADOPOULOU A., JOHN O. S., WILD R., HAMMOND P., AHRENS D., BALKE M., CATERINO M., GÓMEZ-ZURITA J., RIBERA I., BARRACLOUGH T., BOCAKOVAT., BOCAK L. \& VOLGERA. 2007: A comprehensive phylogeny of beetles reveals the evolutionary origins of a superradiation. Science 318(5858): 1913-1916.

HWANG W. S., HANLEY R. S. \& AHN K. J. 2002: Immature stages of Oxyporus germanus Sharp (Coleoptera: Staphylinidae: Oxyporinae). Journal of the Kansas Entomological Society 75(3): 214-221.

KASULE F. K. 1968: The larval characters of some subfamilies of British Staphylinidae (Coleoptera) with keys to the known genera. Transactions of the Royal Entomological Society of London 120(4): 115-138.

KIMURA M. 1980: A simple method for estimating evolutionary rates of base substitutions through comparative studies of nucleotide sequences. Journal of Molecular Evolution 16(2): 111-120.

KOMPANTSEVA T. V. \& SCHIGEL D. 2000: New data on geographic distribution and biology of mycetophilous tenebrionid beetles Eledonoprius Reitter, 1911 (Coleoptera, Tenebrionidae). Russian Entomological Journal 9: 139-141.

KRAATZ G. 1879: Neue Käfer vom Amur. Deutsche Entomologische Zeitschrift 28(1): 121-144

KUMAR S., STECHER G., LI M., KNYAZ C. \& TAMURA K. 2018: MEGA X: molecular evolutionary genetics analysis across computing platforms. Molecular Biology and Evolution 35(6): 1547-1549.

LECONTE J. L. 1861: Classification of the Coleoptera of North America. Smithsonian Miscellaneous Collections 1: i-xxv + 1-286.

LeCONTE J. L., HORN G. H. \& HENSHAW S. 1883: Classification of the coleoptera of North America. Smithsonian Institution, 286 pp.

LESCHEN R. A. \& ALLEN R. T. 1988: Immature stages, life histories and feeding mechanisms of three Oxyporus spp. (Coleoptera: Staphylinidae: Oxyporinae). Coleopterists' Bulletin 42(4): 321-333.

LI J. 1993: [The rove beetles of Northeast China]. Pp. 1-63, 151-163. In: LI J. \& CHEN P. (eds): [Studies on fauna and ecogeography of soil animals (sic)]. Northeast Normal University Press, Changchun, Jilin Province, $265 \mathrm{pp}$ (in Chinese).

LIPKOW E. 1997: Zur Biologie der Ernaehrung, Fortpflanzung, Wirtswahl und Konkurrenzvermeidung von Oxyporus-Arten (Coleoptera: Staphylinidae). Faunistisch-Ökologische Mitteilungen 7: 297-308.

LIPKOW E. 2011: Observations to the life history of dung-inhabiting Staphylinidae (Coleoptera). Faunistisch-Ökologische Mitteilungen 9: 225-246.

MAKAROV K. V. 2002: Chaetotactic markers in the evolutionary morphology of carabid larvae. Russian Entomological Journal 11: $23-34$.

MAKAROV K. V. 2008: Larval chaetotaxy in the genus Rhysodes Dalman, 1823 and the position of Rhysodidae within Adephaga (Coleoptera) Back to the Roots and Back to the Future, Towards a new Synthesis amongst Taxonomic, Ecological And Biogeographical Approaches to Carabidology. Proceedings of the XIII European Carabidologists Meeting, Blagoevgrad, 101-123 pp.

MAKRANCZY Gy. 2012: On the Pseudoxyporus species of East Siberia and description of a new species from China (Coleoptera, Staphylinidae: Oxyporinae). Annales Historico-Naturales Musei Nationalis Hungarici 104: 111-126.

McCABE T. L. \& TEALE S. A. 1981: The biology of Oxyporus lateralis Gravenhorst (Staphylinidae). Coleopterists' Bulletin 35(3): 281-285.

McKENNA D. D., FARREL B., CATERINO M. S., FARNUM C. W., HAWKS D. C., MADDISON D. R., SEAGO A. S., SHORT A. E. Z., NEWTON A. \& THAYER M. 2015: Phylogeny and evolution of the Staphyliniformia and Scarabaeiformia: forest litter as a stepping-stone for diversification of non-phytophagous beetles. Systematic Entomology 40: 35-60.
MEIER R. \& LIM G. S. 2009: Conflict, convergent evolution, and the relative importance of immature and adult characters in endopterygote phylogenetics. Annual Review of Entomology 54: 85-104.

NAKANE T. \& SAWADAK. 1956: A revision of the subfamily Oxyporinae in Japan: Coleoptera: Staphylinidae. Scientific Reports of the Saikyo University, Natural Science and Living Science A(2A): 116-126.

NAVARRETE-HEREIDA J. L. \& NOVELO-GUTIERREZ R. 1990: Contributions to the knowledge of Oxyporinae (Coleoptera: Staphylinidae) associated with mushrooms (Fungi: Basidiomycetes) in Mexico. Coleopterists' Bulletin 44(2): 229-232.

NEWTON A. F. 1984: Mycophagy in staphylinoidea (Coleoptera). Pp. 302-323. In: WHEELER Q. \& BLACKWELL M. (eds): Fungus-Insect Relationships, Perspectives in Ecology and Evolution. Columbia University Press, $514 \mathrm{pp}$.

PAULIAN R. 1941: In: Les premiers états des Staphylinoidea. Editions du museum, Vol. 15, Paris, 361 pp.

PIETRYKOWSKA-TUDRUJ E. \& STANIEC B. 2012: Comparative larval morphology of Platydracus and Staphylinus (Staphylinidae: Staphylinini: Staphylinina) with notes on their biology and redescription of the pupa of Staphylinus. Zootaxa 3580: 24-42.

PIETRYKOWSKA-TUDRUJ E., STANIEC B., WOJAS T. \& SOLODOVNIKOV A. 2014: Immature stages and phylogenetic importance of Astrapaeus, a rove beetle genus of puzzling systematic position (Coleoptera, Staphylinidae, Staphylinini). Contributions to Zoology 83(1): 41-44.

POTOTSKAYA V.A. 1967: Opredelitel'lichinok korotkonadkrylikh zhukov (Staphylinidae) evropeyskoy chasti SSSR. [Classification key of the larvae of Staphylinidae in the European part of the USSR.] Nauka, Moscow, 121 pp (in Russian).

ROBERT V., STEGEHUIS G. \& STALPERS J. 2005-2019: The MycoBank engine and related databases. http://www.mycobank.org [Accessed 24 September, 2019.]

SCHEERPELTZ O. \& HÖFLER K. 1948: Käfer und Pilze. Verlag für Jugend und Volk, Vienna, $351 \mathrm{pp}$.

SCHIØDTE J. M. 1864: De metamorphosis eleutheratorum observationes. Thieles bogtrykkeki, Vol. 2, København, pp. 118-119, pl. 11, fig. 1.

SETSUDA K. 1994: Construction of the egg chamber and protection of the eggs by female Oxyporus japonicus Sharp (Coleoptera, Staphylinidae, Oxyporinae). Japanese Journal of Entomology 62(4): 803-809.

SHIBATA Y. 1976: Provisional check list of the family Staphylinidae of Japan. I. Annual Bulletin of the Nichidai Sanko 19: 71-212.

SCHÜLKE M. 2017: Oxyporus-Studien-II. Oxyporus (Oxyporus) procerus Kraatz und O. (Oxyporus) ruzickai spec. nov. aus China (Coleoptera, Staphylinidae, Oxyporinae). Beiträge zur Entomologie = Contributions to Entomology 67(2): 355-361.

SOLODOVNIKOV A. 2007: Larval chaetotaxy of Coleoptera (Insecta) as a tool for evolutionary research and systematics: less confusion, more clarity. Journal of Zoological Systematics and Evolutionary Research 45(2): 120-127.

THAYER M. K. 1985: The larva of Brathinus nitidus LeConte and the systematic position of the genus (Coleoptera: Staphylinidae). Coleopterists' Bulletin 39(2): 174-184.

THAYER M. K. 2016: 14. Staphylinoidea. 14.7. Staphylinidae Latreille, 1802. Pp. 394 442. In: BEUTEL R. G. \& LESCHEN R. A. B. (eds): Handbook of Zoology, Arthropoda: Insecta; Coleoptera, Beetles. Morphology and Systematics (Archostemata, Adephaga, Myxophaga, Polyphaga partim)). 2nd ed. De Gruyter, Berlin, 684 pp.

TIKHOMIROVAA. L. 1973: Morfoecologicheskie osobennosti i filogenez stafilinid (s katalogom fauni SSSR) [Morphoecological aspects and the phylogenesis of staphylinids (with the catalogue of USSR fauna)]. Nauka, Moscow, 91 pp (in Russian).

TIKHOMIROVAA. L. \& MELNIKOV O. A. 1970: Late embryogenesis of Staphylinidae and nature of aleocharo-and staphylinomorphous larvae. Zoologischer Anzeiger 184-186: 74-76.

VAN EMDEN F. I. 1957: The taxonomic significance of the characters of immature insects. Annual Review of Entomology 2: 91-106.

WEINREICH E. 1968: Über den Klebfandapparat der Imagines von Stenus Latr. (Coleopt.; Staphylinidae) mit einem Beitrag zur Kenntnis der Jugendstadien dieser Gattung. Zoomorphology 62(2): 162-210.

YUH J.-H., PAIK W. H., KWON Y. J. \& LEE S.-M. 1985: Check list of rove beetles from Korea (Coleoptera: Staphylinidae). Insecta Koreana 5: 223-255. [Note: Date of publication: May 29, 1985].

YUE Y.-L., REN D. \& SOLODOVNIKOV A. 2011: The oldest fossil species of the rove beetle subfamily Oxyporinae (Coleoptera: Staphylinidae) from the Early Cretaceous (Yixian Formation, China) and its phylogenetic significance. Journal of Systematic Palaeontology $\mathbf{9}$ : 467-471. 